\title{
ESTUDOS ECOFISIOLÓGICOS DE Orchidaceae DA AMAZÔNIA. II - ANATOMIA ECOLÓGICA FOLIAR DE ESPÉCIES COM METABOLISMO CAM DE UMA CAMPINA DA AMAZÔNIA CENTRAL.
}

\author{
Luiz Carlos de Matos BONATES ${ }^{1}$
}

\begin{abstract}
RESUMO - Este trabalho é o segundo de uma série que objetiva correlacionar a anatomia foliar e via de fixação de $\mathrm{CO}_{2}$ com a distribuição geográfica de Orchidaceae e especificamente, detectar a existência de suculência nas espécies estudadas e também qualificá-las na classificação anatômica de WITHNER et al. (1974). Enfoca-se características anatômicas que possivelmente se relacionariam com o xeromorfismo habitacional e/ou escleromorfismo nutricional e via fotossintética CAM, e estas estabeleceriam uma síndrome adaptativa para o efetivo controle do fluxo hídrico no limbo foliar, dando para as espécies condições para a colonização de ambientes mais xéricos como os da Campina aberta. Detectou-se a presença de suculência anatômica propícia para a ocorrência do metabolismo CAM, sendo que as folhas foram classificadas como sendo do tipo Coriáceas.
\end{abstract}

Palavras-chave: Anatomia ecológica, Ecofisiologia, Orchidaceae, Campina, CAM.

Ecophysiological Studies of Orchidaceae in Amazonia. II - Ecology of Leaf Anatomy of Species with Cam Metabolism in a Central Amazonian White Sand Campina.

ABSTRACT - This paper is the second in a series which discusses the leaf anatomy and mode of fixation of $\mathrm{CO}_{2}$ in relation to the geographic of Orchidaceae, and specifically describes the occurence of succulence in the species studied, and classifies them according to the anatomical system of WITHNER et al. (1974). The anatomical characteristics which might related to behavioural and/or nutritional sclerophism and CAM photoshyntesis are examined, and these are found to form an adaptative syndrome for the control of water flow through the leaf surface, allowing these species to colonize the drier habitats such as the open campina. Succulence is a characteristic of plants with CAM metabolism, and the leaves were classified as being coriaceous.

Key-words: Ecological anatomy, Ecophysiology, Orchidaceae, Campina, CAM.

\section{INTRODUÇÃO}

Poucos trabalhos foram realizados em busca de dados anatômicos e fisiológicos sobre espécie ocorrentes em Campina da Amazônia Brasileira, entre os quais os de FERRI (1960), que trabalhou com anatomia ecológica, onde analisou o padrão de abertura estomática, transpiração cu- ticular e anatomia foliar de espécies de uma "caatinga do Rio Negro (Amazonas)" e MORRETES \& FERRI (1972) que descreveram a anatomia foliar de algumas espécies que ali ocorriam. BRAGA \& BRAGA (1975) estudaram duas espécies de Loranthaceae hemiparasitas nas Campinas com tendências a possuírem hospedeiros específicos, analisando,

Instituto Nacional de Pesquisas da Amazônia, Coordenação de Pesquisas em Botânica, Caixa Postal 478, 69011-970, Manaus, Amazonas, Brasil. 
anatômicos e ecofisiológicos. BRAGA (1977) estudou a anatomia foliar de algumas espécies de Bromeliaceae e VILHENA (1978) fez a anatomia foliar de algumas espécies de Humiriaceae que ali ocorrem. BRAGA \& VILHENA (1981) estudaram a anatomia ecológica de Epidendrum huebneri Schltr. (Orchidaceae) e Phthirusa micranta Eichl. (Loranthaceae), analisando alguns aspectos ecofisiológicos das duas espécies.

O presente trabalho é o segundo de uma série que visa proporcionar dados para o entendimento da correlação da via de fixação de $\mathrm{CO}_{2}$ e anatomia ecológica foliar com a distribuição espacial de algumas Orchidaceae que vegetam no estrato terrestre de uma Campina da Amazônia Central dando continuidade aos estudos realizados no referido ecossistema por BRAGA (1977, 1982b, 1987a), e BONATES \& BRAGA (1992), e especificamente detectar a existência de suculência anatômica nas espécies discriminadas no primeiro trabalho da citada série (BONATES \& BRAGA, 1992) como possuidoras da via de fixação de carbono do tipo CAM (Crassulaceam Acid Metabolism), assim como, qualificar as folhas das referidas espécies na classificação anatômica baseada em WITHNER et al. (1974).

Sabe-se que os fatores físicos não atuam isoladamente em um ser vivo, mas de forma inter-relacionada, tornando-se difícil determinar qual deles induz um efeito adaptativo. Ao estudar-se anatomicamente as Orchidaceae, nota- se que as mesmas possuem vários caracteres que são adaptativos, na sua maioria de natureza morfo-genética que seriam selecionados durante o desenvolvimento do espécime, como sugerido por ZIEGENSPECK (1938) para a ocorrência de características estomáticas xeromórficas em Orchidaceae; MEDRI (1977, 1980) chama atenção para que caracteres aparentemente xeromórficos nem sempre indicam xerofilia. Estes caracteres também são comuns em condição de esclerofilia causada por fatores como a pobreza de nutrientes no solo (MEDINA et al., 1990), assim como a grande quantidade de alumínio no solo (GOODLAND, 1971), nominando-se este fenômeno de escleromorfismo oligotrófico e, em sendo os solos da Campina oligotróficos, é possível que este fenômeno ocorra nas Orchidaceae deste ecossistema, sendo que LLERAS (1978), baseado no trabalho de MAXIMOV (1931), lista uma série de características conhecidas como lei de ZALENSKI, que são comumente relacionadas com xerofilia e esclerofilia, que são: células menores, maior número de estômatos por unidade de área, paredes mais espessas e menos sinuosas nas células epidérmicas, diferenciação mais marcante entre tecidos paliçádico e esponjoso, menor espaço intercelular. tecido mecânico mais desenvolvido, maior venação por unidade de área, tamanho de folha, mesofilo mais espesso.

MEDINA (1987) reporta que a sobrevivência de plantas CAM em habitats com uma estação seca prolongáda está mais relacionada à sua estrutura anatômica do que a 
capacidade do metabolismo CAM se desenvolver adequadamente frente a condições de baixo potencial hídrico. Um caráter anatômico importante da relação xerofilia e metabolismo CAM é a ocorrência de suculência, que é uma das condições necessárias para o funcionamento do mesmo. É importante ressaltar que esta suculência não implica, necessariamente, em uma carnosidade aparente, mas sim em uma suculência anatomicamente detectável no clorênquima, que deverá possuir células clorofiliana grandemente vacuolizadas, com cloroplastos periféricos (COUTINHO, 1969; MEDINA, 1974, 1977; AVADHANI et al., 1980; WIESBERG, 1981; COOMBS \& HALL, 1987).

\section{MATERIAL E MÉTODOS}

\section{Local de coleta}

O presente trabalho foi realizado com material coletado na Reserva Biológica de Campina do INPA/ SUFRAMA, BR-174, $\mathrm{km} 45$, estrada Manaus-Caracaraí $2^{\circ} 30^{\prime} 00^{\prime \prime} \mathrm{S}$, longitude $60^{\circ} 00^{\prime} 00^{\prime \prime} \mathrm{W}$ e altitude de 44 metros (RIBEIRO \& SANTOS, 1975)

\section{Espécies Estudadas}

Foram estudadas seis espécies de Orchidaceae ocorrentes no substrato terrestre da vegetação de Campina aberta e Campina sombreada da Reserva Biológica INPA/ SUFRAMA, e discriminadas como plantas CAM por BONATES \& BRAGA (1992), a saber: Brassavola martiana (INPA) 51.125, Cattleya eldorado Linden (INPA) 49.736,
Encyclia tarumana (INPA) 49.728, Encylia vespa (Vell.) Dressl. (INPA) 51. 086, Epidendrum compressum Griseb (INPA) 49.735, Epidendrum huebneri Schltr. (INPA) 49.727.

Utilizou-se folhas perfeitamente desenvolvidas destes indivíduos, sendo que os dados obtidos são inéditos para todas as espécies estudadas, excetuandose Epidendrum huebneri Schlttr., que foi submetida a estudo semelhante por BRAGA \& VILHENA (1981). Salienta-se que muitas destas Orchidaceae possuem o hábito epifítico, mas por vários fatores, caem do seu substrato e encontram no estrato terrestre de Campina, condiçōes ideais de sobrevivência, tais como intensidade luminosa e drenagem. Os gêneros constantes neste trabalho estão de acordo com PABST $\&$ DUNGS $(1975,1977)$. A discriminação de via de fixação de $\mathrm{CO}_{2}$, CAM feita por BONATES \& BRAGA (1992), utilizou a combinação de vários métodos quantitativos precisos (discriminação do ${ }^{13} \mathrm{C}^{12} \mathrm{C}$ e resistência dos estômatos) com o método qualitativo da via de fixação de $\mathrm{CO}_{2}$ (colorimétrico de Kauko), a fim de reforçar a validade qualitativa deste último (Tab. 1).

\section{Estudo anatômico foliar}

Dissociação de epidermes - Foram tomadas três a cinco folhas de cada indivíduo e divididas em quatro regiões (meio-base, meio-meio, meiomargem, meio-ápice) retirando-se quadrados de $1 \mathrm{~cm}$. A seguir, os pedaços foram dissociados em mistura de Jeffrey, corados em Astrablau-Fucsina (BRAGA, 1977), desidratados e montados em gelatina glicerinada 


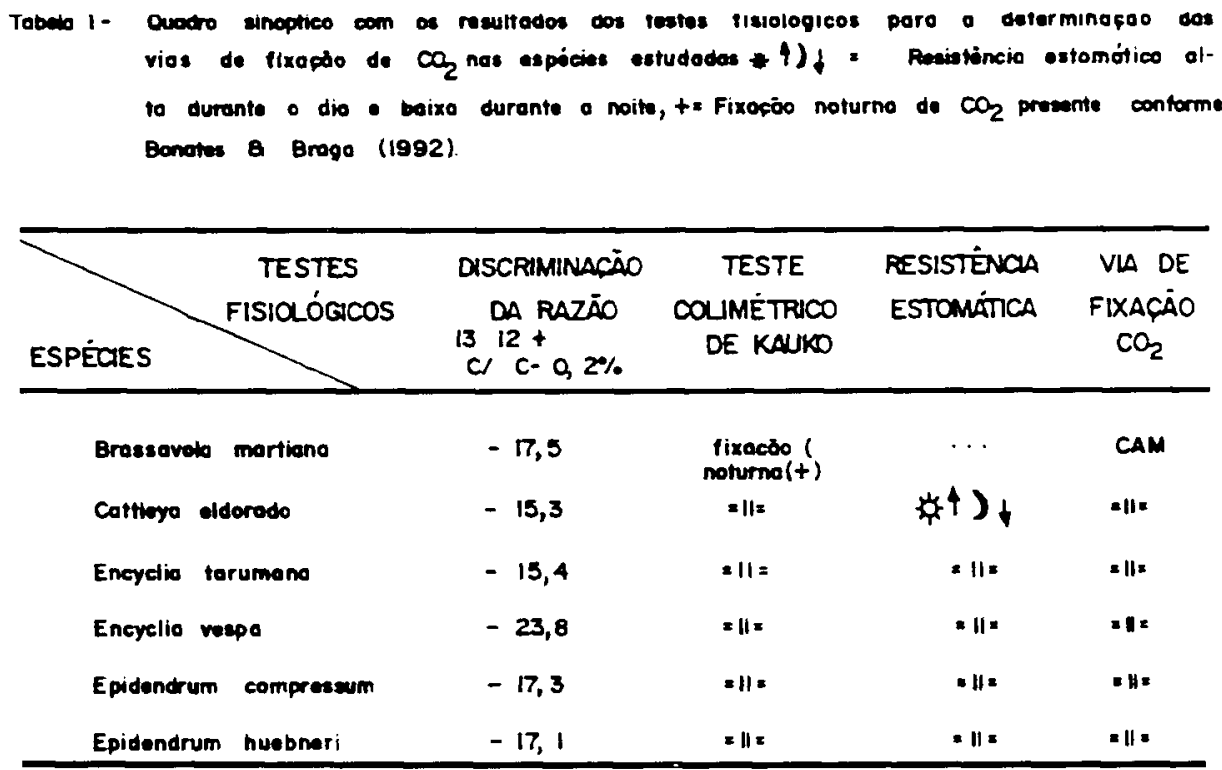

(JOHANSEN, 1940), sendo que para as contagens e mediçóes, utilizou-se um microscópio ZEISS com objetiva de 40x ocular 10x para as medições, que foram feitas com régua micrometrada ZEISS, sendo as contagens dos estômatos feitas com uma objetiva de $25 \mathrm{x}$ ocular $10 \mathrm{x}$, utilizando-se cerca de três campos por folha.

Cortes histológicos - Para os cortes em parafina e congelação, utilizou-se respectivamente os micrótomos rotativos de R. Jung e American Optical Corporation. $\mathrm{Na}$ microtomia com parafina, foram utilizadas as quatro regiões da folha, descritas anteriormente. O fixador usado foi o álcool $70 \%$, sendo que a desidratação e inclusão de parafina foram feitas pelos métodos usuais de anatomia, sendo posteriormente desparafinados, corados em Astrablau-Fucsina, desidratados em série alcoólica e montados em bálsamo do Canadá ou Verniz-Cristal. Utilizou-se, ainda, a microtomia de congelação, trabalhando-se com material vivo das mesmas regiões já mencionadas, incluindo-se em cola vinílica diluída em água, na proporção de 1:1, à temperatura de $-15^{\circ} \mathrm{C}$, corando-se os cortes com Astrablau-Fucsina e montando-se em bálsamo do Canadá ou em Verniz-Cristal. Adicionalmente, foram feitos cortes à mão livre, com lâminas de barbear, descorados com água sanitária com algumas gotas de água, corados em Astrablau-Fucsina e montados em gelatina glicerada. Os desenhos esquemáticos e as fotomicrofias foram feitas através de uma câmara clara e fotográfica MC63 ZEISS adaptada a um microscópio ZEISS, em vários aumentos. As classificações anatomo-ecológicas foram feitas baseadas nos trabalhos de WITHNER et al. (1974), onde introduziu-se modificações, pois algumas caracteristicas morfológicas e ecológicas apresentadas pelo referido autor, não se enquadram em todas as 
características neste trabalho. Utilizouse ainda os trabalhos de BRAGA (1982b) e LLERAS 1978, como suporte e o de RASMUSSEN (1987) para a classificação dos estômatos.

Testes microquímicos - Os testes utilizados foram os de JOHANSEN (1940), como segue:

- Floroglucina/Ácido acético: cora de vermelho a lignina.

- Sudam III: cora de vermelho a cutina.

Teste óptico - Utilizou-se a luz polarizada para a visualização de inclusões cristalinas (PRIDGEON, 1982).

\section{RESULTADOS}

\section{Brassavola martiana Lindl.}

Habitat e morfologia - Epífita a terrestre secundária na Campina sombreada e Campina aberta, heliófila e semi-umbrófila. Folha única disposta no ápice de pseudobulbo roliço e quase imperceptível, arcuada a ereta, persistente, filiforme, subereta, sulcada, alongada, estreita, ca. de $23-30 \mathrm{~cm}$ de comprimento, ca. de $0,5-1 \mathrm{~cm}$ de altura, raiz com velame.

\section{Descrição anatômica}

Epiderme - Ambas as epidermes, em vista frontal, são constituídas de células irregulares quanto ao formato e ao tamanho, com paredes espessas, orientadas perpendicularmente ao comprimento foliar (Fig. I A e B). Em vista transversal, as epidermes são uniestratificadas, com células tabulares, aclorofiladas, apresentando um forte espessamento celulósico e providas de algumas células contendo vacúolosráfides com cristais de oxalato de cálcio, assim como raras células esclerificadas. As epidermes estão recobertas por uma cutícula espessa, contínua por toda a folha, ondulada e com ranhuras perpendiculares à epiderme. As epidermes possuem pequenos espaços intercelulares pouco diferenciados, que são preenchidos pela cutícula (Fig. 1 C). Nota-se a presença de pontuações nas paredes anticlinais, próximo à região em que as ditas paredes encontram-se com a periclinal interna. Estas pontuações formam uma linha contínua através das células da epiderme (Fig. 2 C). As folhas são anfistomáticas, com maior predominância estomática na epiderme abaxial (média de 30,3 de estômatos por campo) em relação à adaxial (média de 23,2 de estômatos por campo). Os estômatos são paralelos à nervura, paracíticos, esféricos, solitários ou geminados, sendo que estes últimos apresentam-se com certa frequência. Os estômatos estão situados ao nível das células da epiderme, possuindo câmaras subestomáticas e mostram uma acentuada projeção cuticular que, vista em corte transversal, no primeiro plano, possui a forma de "garra", assim como um acentuado espessamento celulósico nas células-guardas. A projeção cuticular forma pequenos poros de formato oblongo, quando observada em vista frontal (Fig. 2 A). Não foi notada a presença de tricomas.

Clorênquima - Situado logo abaixo das epidermes. É homogêneo, com células poliédricas, de tamanho irregular, com as paredes anticlinais 
com espessamento celulósico acentuado em relação às paredes periclinais. As células não são paralelas às da epiderme e possuem grandes vacúolos, ocorrendo ainda várias células incolores, sem cloroplastos, dispersas pelo mesófilo, parecendo estar relacionadas com a reserva de água. Não apresentam uma clara distinção entre células paliçadas e lacunosas, sendo que na região de nervura central, as células tendem a alongar suas paredes anticlinais e, na região do mesófilo inferior, por toda a folha, as células são mais isodiamétricas, constituindo-se o mesofilo por um compacto clorênquima, com espaços intercelulares do tipo meato. Os cloroplastos aparentam nào possuir dimorfismos, estando agrupados ou não, dentro do citoplasma, distribuindose de maneira uniforme por todo o clorênquima.

Condução e sustentação - Os feixes fibrovasculares, formam três camadas medianas com a seguinte configuração: a camada intermediária ocupa o meio do mesófilo e é onde está contida a nervura central e também os maiores feixes fibrovasculares, que vão diminuindo paulatinamente de diâmetro à medida que se aproxima da periferia. As ouiras duas camadas, uma superior e outra inferior à camada do meio, possuem a mesma configuração. sendo que nelas, os feixes são praticamente do mesmo diâmetro. As camadas de feixes tendem a acompanhar o formato conduplicado da folha (Fig. 3 A e 2 B). Nos feixes fibrovasculares, o xilema é superior ao floema, sendo um contíguo ao outro. Estão en- volvidos de parênquima esclerificado e de fibras esclerenquemáticas densamente espessadas, que nos polos dos feixes formam capas, apresentando-se a do floema maior que a do xilema (Fig. 3 B). O xilema apresenta vasos com reforço escalariforme, em predominância ao reforço helicoidal. Encontram-se por toda a periferia da folha. duas camadas de fibras esclerenquimáticas, sendo uma mais externa que possui ninhos em torno de onze fibras, e a outra mais interna, localizada três camadas de células abaixo da primeira, com ninhos constituídos de dezoito células, que não possuem suas fibras densamente desenvolvidas. As duas camadas intercalaram-se e. suas fibras, tais como as fibras periféricas dos feixes fibrovasculares, possuem grande e conspícuas pontuações (Fig. 2 B e 3 B). Nas demais regiões da folha ocorre a mesma disposição dos tecidos descritos anteriormente.

\section{Cattleva eldorado Linden.}

Habitat c morfologia - Epifita a terrestre secundária na Campina aberta e sombreada, umbrófila a heliófila. Folhas dispostas no ápice do pseudobulbo, uni ou bifoliadas. eretas. persistentes coriáceo-carnosas, oblongas, alongadas, largas ca. de $5-25 \mathrm{~cm}$ de comprimento, cat de $3-4 \mathrm{~cm}$ de largura, raiz com velame.

\section{Descrição anatômica}

Epiderme - Ambas as epidermes. em vista frontal, säo constituidas de células quanto ao formato e tamanho. com paredes espessadas, orientadas perpendicularmente ao comprumento 

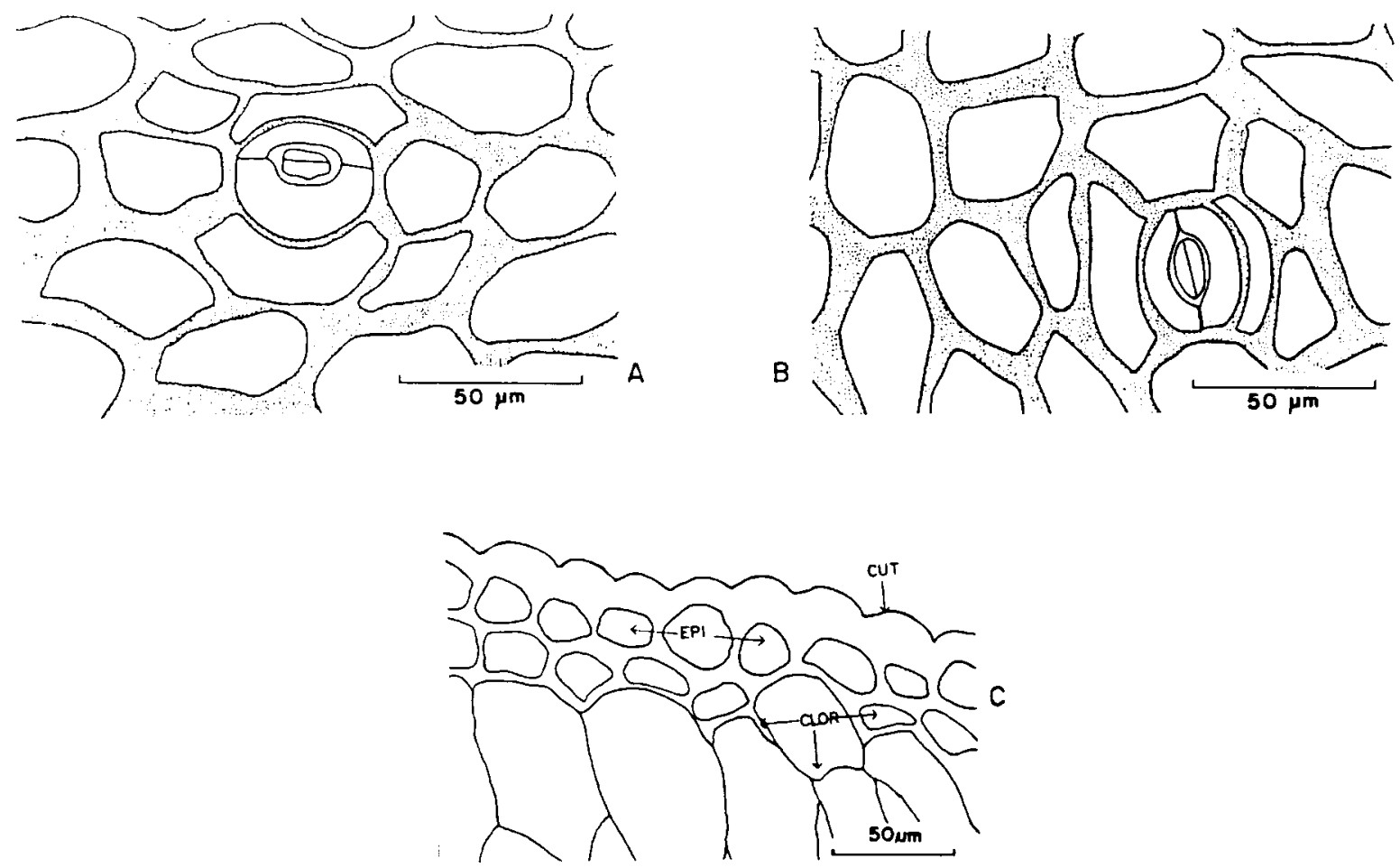

Figura 1. Folha da Brassavola martiana Lindl. A: Epiderme adaxial em vista frontal. B: Epiderme abaxial. C: Corte transversal mostrando parte do mesofilo superior; CUT = Cutícula; $E P I=$ Epiderme; $C L O R=$ Clorênquima. 

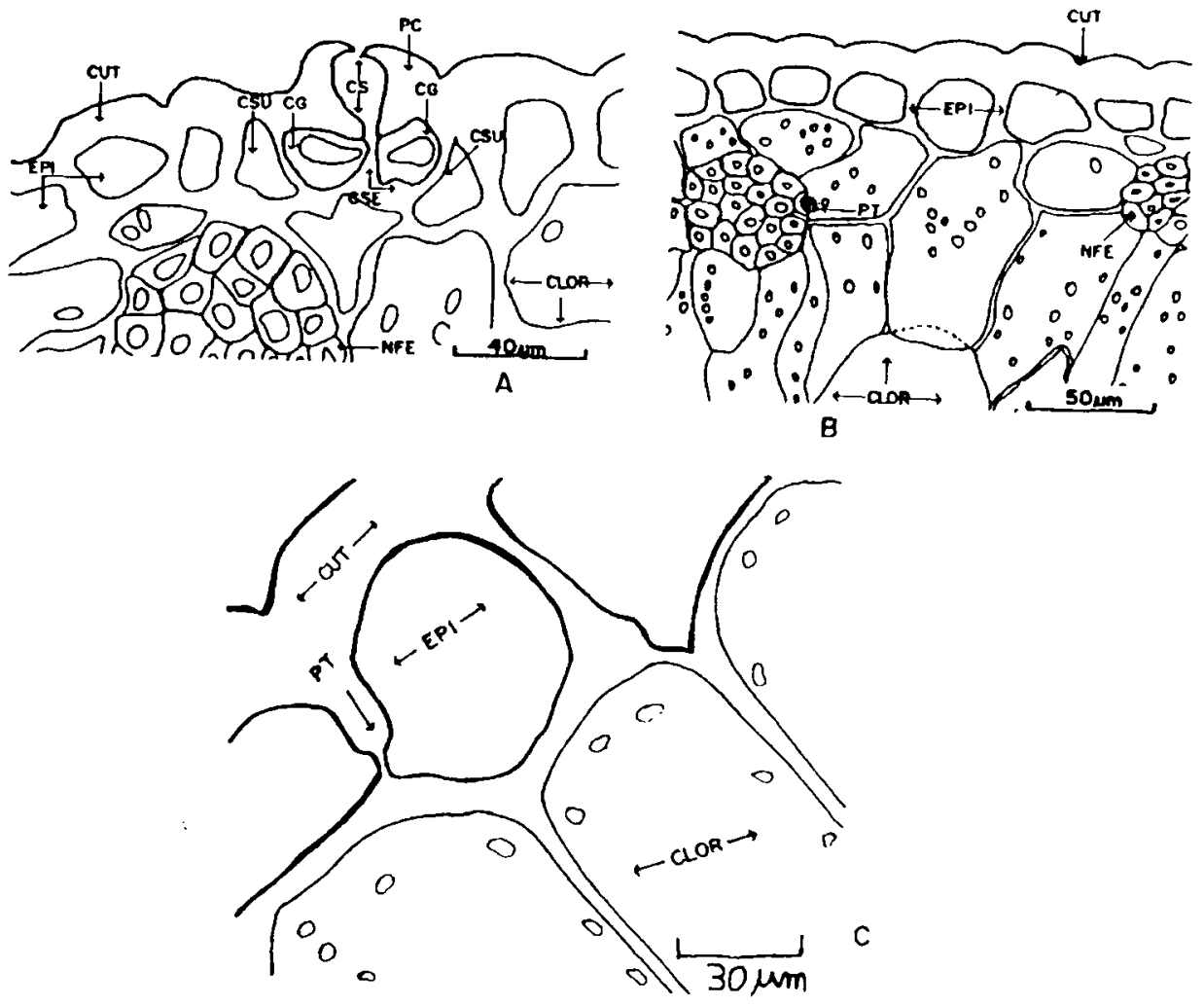

Figura 2. Folha de Brassavola martiana Lindl. em corte Transversal. A: Face abaxial. CUT = Cutícula; $\mathrm{PC}=$ Projeção cuticular; $\mathrm{CS}=$ Câmara supraestomática; $\mathrm{CSE}=$ Câmara subestomática; $\mathrm{CE}=$ Células-guardas; $\mathrm{CSU}=$ Células subsidiárias; $\mathrm{EPI}=$ Epiderme; $\mathrm{CLOR}=$ Clorênquima; NFE $=$ Ninho de fibras esclerenquimáticas. B: Mesofilo inferior. CUT = Cutícula; $\mathrm{EPI}=$ Epiderme; NFE = Ninho de fibras esclerenquimáticas; PT = Pontuação; CLOR = Clorênquima. C: Detalhe das células de epiderme mostrando pontuação na parede anticlinal. CUT = Cutícula; $\mathrm{EPI}=$ Epiderme; CLOR = Clorênquima; $\mathrm{P}=$ Pontuação. 


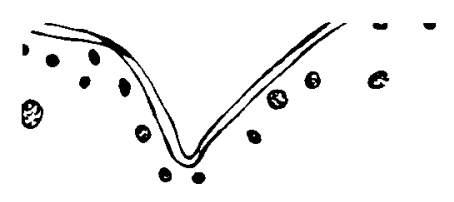

0

)

0

$>$

0

0

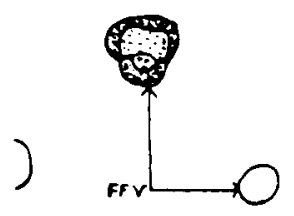

0

- 0

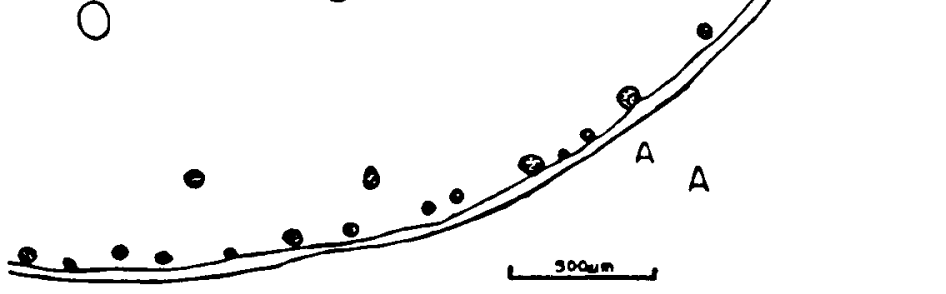

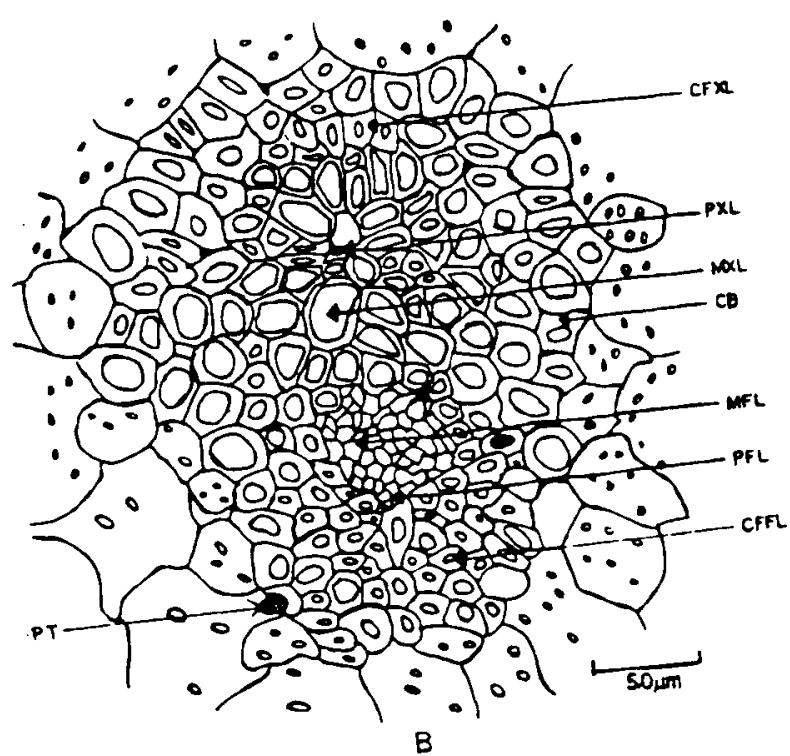

B

Figura 3. Corte Transversal da Folha de Brassavola martiana Lindl. A: Esquema da Disposição dos tecidos de Condução e Sustentação. NFE $=$ Ninhos de Fibras Esclerenquimáticas; FFV = Feixe Fibrovascular. B: Esquema de um Feixe Fibrovascular. CFXL = Capa de Fibras do Xilema; PXL = Protoxilema; $\mathrm{MXL}=$ Metaxilema; $\mathrm{CB}=$ Células da Bainha; $\mathrm{MFL}=$ Metafloema; $\mathrm{PFL}=$ Protofloema; $\mathrm{CFFL}=$ Capa de Fibras do Floema; PT= Pontuaçōes. 
foliar (Fig. 4 A e B). Em vista transversal, as epidermes são uniestratificadas, com células tabulares, aclorofiladas, com as células da epiderme adaxial maiores e possuindo um espessamento mais acentuado na parede periclinal externa, do que as epidermes abaxial. As epidermes estão recobertas por uma grossa cutícula ondulada, com ranhuras perpendiculares à epiderme, sendo a adaxial mais espessa e cheia de fendas. Existem espaços intercelulares pouco diferenciados, que podem ir desde 1/4 das paredes anticlinais até a total separação das células, o que é mais raro. A porção da cutícula que entra em contato com a parede periclinal externa das células apresenta um reforço de suberina. Nota-se que algumas células epidérmicas esclerificam-se e que inexistem tricomas em ambas as epidermes. As folhas são hipoestomáticas, com estômatos paracíticos (média de 3 estômatos por campo), esféricos, situados a nível das células da epiderme com projeção cuticular acentuada que, em visão transversal, em primeiro plano, apresenta a forma de garra. Possuem câmaras supra e subestomáticas. As células estomáticas possuem cloroplastos e apresentam um forte reforço celulósico. A projeção cuticular forma pequenos poros de ar de formato oblongo ou obovado, quando observada em vista frontal (Fig. 4 B e C). Os estômatos obedecem a uma difusa orientação, paralela ao comprimento foliar e estão distribuídas heterogeneamente no limbo.

Hipoderme - Situada logo abaixo das duas epidermes, sendo que suas paredes anticlinais e, esporadicamente, as periclinais externas, apresentam-se esclerificadas, possuindo barras de espessamento de lignina. As hipodermes apresentam-se constituídas de uma a três camadas de células, com o espessamento secundário diminuindo gradativamente nas camadas mais internas (na face abaxial, esta gradação penetra até aproximadamente a quinta camada de mesófilo), sendo seus citoplasmas incolores e com algumas células apresentando cloroplastos (Figs. 4 C, 5 A).

Clorênquima - Situado logo abaixo das hipodermes, com suas células intercalando-se com as mesmas. É homogêneo, com células poliédricas de tamanho irregular e paredes finas, algumas com espessamento secundário e com conspícuas pontuações nas paredes periclinais. O Clorênquima não apresenta uma clara distinção entre células lacunosas e paliçádicas, sendo que na região da nervura central as células do mesofilo superior tendem alongar suas paredes anticlinais e, na região do mesofilo inferior, por toda a folha, as células são mais isodiamétricas, constituindo-se o mesofilo de um compacto clorênquima, com espaços intercelulares do tipo meato (Fig. 5 A). Os cloroplastos não aparentam possuir dimorfismos, estando agrupados ou não dentro do citoplasma e distribuídos de maneira uniforme por todo o clorênquima. Existem ainda células, em grupos ou não, incolores, sem cloroplastos, grandemente vacuolizadas, dispersas 
pelo mesofilo e situadas em geral, próximo a algum grande feixe fibrovascular, que parecem estar relacionados com a armazenagem de água. Nota-se ainda a presença sempre constante de vacúolos com cristais de oxalato de cálcio em forma de ráfides, dispersos por todo o mesofilo, assim como a presença de algumas células do clorênquima próximas à hipoderme que apresentam barras de espessamento de lignina.

Condução e sustentação - Os feixes fibrovasculares formam duas camadas medianas com a seguinte configuração: as duas são paralelas e oblíquas em relação à nervura central (localizada no mesofilo inferior, cinco camadas acima da epiderme abaxial). Os feixes de maior diâmetro estão voltados para a epiderme abaxial e os menores para a adaxial, sendo que as duas camadas estão bem próximas e seus elementos intercalam-se em relação ao eixo transversal da folha (Fig. 5 B). Os feixes apresentam o xilema superior ao floema, que estão separados por um fino cordão de células esclerenquimáticas e o xilema apresenta elementos tranqueais escalariformes predominando sobre o helicoidal. Os feixes possuem ainda parênquima esclerificado e fibras fortemente espessadas que formam espessas capas, sendo a do floema maior que a do xilema (Fig. $5 \mathrm{C}$ ). Encontra-se intercalado com a hipoderme abaxial, uma superficial camada de ninhos de fibras esclerenquimáticas composto em média de vinte fibras. Estes ninhos e os feixes fibrovasculares, possuem em suas fibras periféricas, grandes e conspícuas pontuações. Nas demais regiões da folha, ocorre a mesma disposição dos tecidos descritos anteriormente.

\section{Encyclia tarumana Schltr.}

Habitat e morfologia Pseudoterrestre na Campina aberta e sombreada, heliófila e umbrófila. Pseudobulbos presentes, bifoliada no ápice do pseudobulbo, folhas coriáceocarnosas, suberetas, persistentes, oblongo-ensiformes, alongadas, estreitas, ca. de $10-15 \mathrm{~cm}$ de comprimento, ca. de $0,4 \mathrm{~cm}$ de lagura, raiz com velame.

\section{Descrição anatômica}

Epiderme - Ambas as epidermes, em vista frontal, são constituídas de células irregulares quanto ao formato e tamanho, com paredes retas, grossas (sendo a abaxial de maior espessura), orientada perpendicularmente ao comprimento foliar (Fig. 6 A e B). Em vista transversal, as epidermes são uniestratificadas, com células aclorofiladas, sendo que as células da adaxial sāo maiores. As epidermes estão recobertas por uma cutícula não muito espessa, ornamentada, ondulada, com ranhuras perpendiculares à epiderme, sendo a da epiderme adaxial mais grossa que a da abaxial. As epidermes possuem pequenos espaços intercelulares pouco diferenciados que são preenchidos pela cutícula. Nota-se ainda, que algumas células, nas duas epidermes, esclerificam-se, principalmente na região da nervura central. 

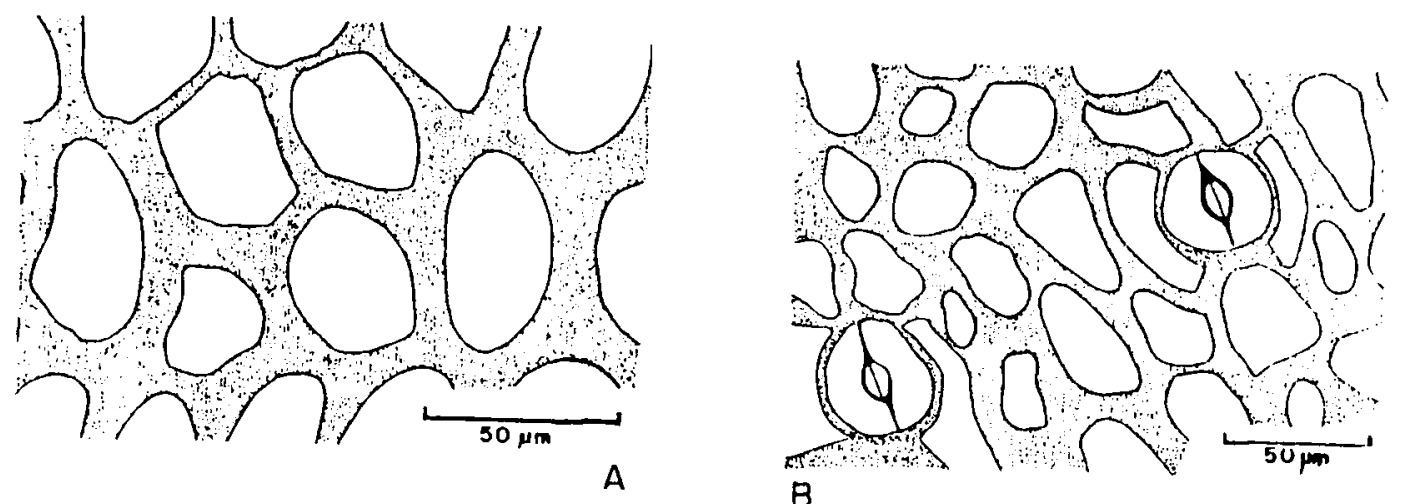

$B$

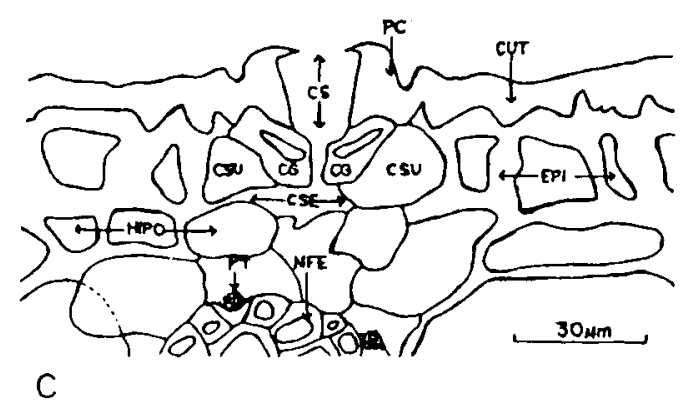

Figura 4. Folha de Cattleya eldorado Linden. A: Epiderme adaxial em vista frontal. B: Epiderme abaxial. C: Corte transversal na face abaxial. CLT = Cutícula; $\mathrm{PC}=$ Projeção cuticular; $\mathrm{CS}=$ Câmara supra estomática; $\mathrm{CG}=$ Células-guardas; $\mathrm{CSE}$ = Câmara subestomática; $\mathrm{CSU}=$ Células subsidiárias; IPI = Epiderme; HIPO = Hipoderme; $\mathrm{NFE}=$ Ninho de fibras esclerenquimáticas; PT = Pontuação. 



$\mathrm{B}$

A

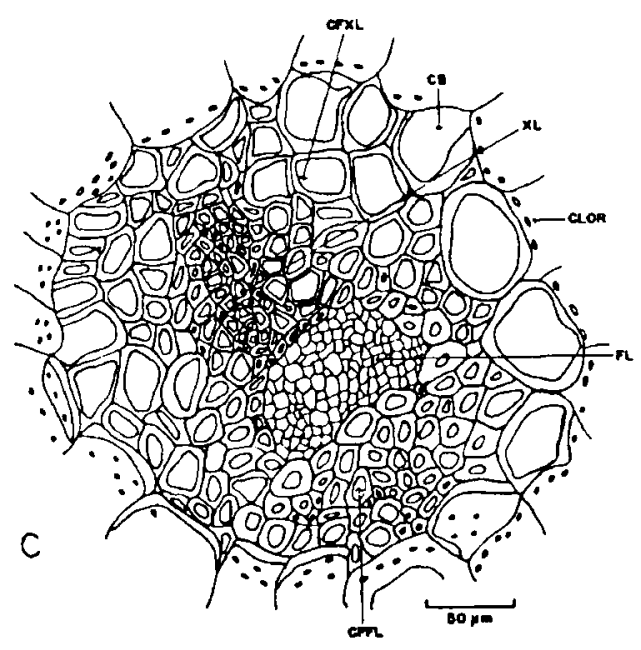

Figura 5. Folha de Cattleya eldorado Linden. A: Corte transversal na região do meio. CUT = Cutícula; HIPS = Hipoderme superior; CLOR = Clorênquima; FFV = Feixe fibrovascular; NFE $=$ Ninho de fibras esclerenquimáticas; HIPI = Hipoderme inferior; EAD = Epiderme adaxial. $\mathbf{B}$ : Corte transversal mostrando a nervura principal e a disposição dos tecidos de condução e sustentação; FFV = Feixe fibrovascular; NFE = Ninho de fibras esclerenquimáticas. $\mathbf{C}$ : Corte transversal de um feixe fibrovascular; $\mathrm{CFXL}=$ Capa de fibras do xilema; $\mathrm{CB}=$ Células das bainha; $\mathrm{XL}=$ Xilema; $\mathrm{CLOR}=$ Clorênquima; $\mathrm{FL}=\mathrm{Floema} ; \mathrm{CFFL}=\mathrm{Capa}$ de fibras do floema. 
Vê-se abundância de pontuação nas paredes anticlinais e reforço de suberina nas paredes periclinais externas de ambas as epidermes. As folhas são hipoestomáticas (média de 82,2 de estômatos por campo). Os estômatos são paracíticos, com distribuição paralela à nervura, são esféricos e solitários, aparecendo estômatos geminados de maneira esporádica, estando os estômatos imersos ao mesmo nível das células da epiderme e possuindo pequenas câmaras subestomáticas e supraestomáticas, apresentando uma pequena projeção cuticular acentuada que, observada em corte transversal, em primeiro plano, possui a forma de "garra", assim como um acentuado espessamento celulósico nas células-guardas. A projeção cuticular forma pequenos poros de formato obovados ou arredondados, quando observada em vista frontal (Fig. $6 \mathrm{~A}$ e C). Ocorrem tricomas desde a base até o ápice, de maneira inconstante, na epiderme abaxial. São solitários, pluricelulares, constituídos de duas a três células, sendo a base formada por duas células, estando a mesma em depressões, e o corpo constituído de uma grande célula que tem as paredes reforçadas e citoplasma mucilaginoso. Os tricomas não apresentam características excretoras e são caliciformes.

Hipoderme - Logo abaixo das epidermes encontra-se uma hipoderme. As hipodermes adaxial e abaxial são constituídas de duas a três camadas de células, sendo que as células da abaxial são distintamente menores que as da adaxial. Ambas as hipodermes apresentam várias células com espessamento secundário de lignina, principalmente na nervura central, incolores, com poucos ou nenhum cloroplasto. Nota-se a presença de pontuações nas paredes anticlinais.

Clorênquima - Situado logo abaixo das hipodermes, é homogêneo, com células poliédricas de tamanho irregular, com paredes finas, não sendo paralelas à epiderme. Possui suas células grandemente vacuolizadas, com citoplasma periférico, não apresentando uma clara distinção entre células paliçádicas e lacunosas, sendo que na região da nervura central e mesofilo superior, as células tendem a alongar suas paredes anticlinais e, nas regiōes do mesofilo inferior, por toda a folha, as células são mais isodiamétricas (Fig. 7 A). O mesofilo é constituído de um compacto clorênquima, com espaços intercelulares do tipo meato e alguns canais. Nota-se a presença de pontuações nas paredes anticlinais das células do clorênquima. Os cloroplastos aparentam não possuir dimorfismos. estando agrupados ou não dentro do citoplasma e distribuídos de maneira irregular por todo o clorênquima.

Condução e sustentação - Os feixes fibrovasculares formam uma camada mediana a partir da nervura central, que está situada num nível mais inferior e, a partir dela, configurase uma camada formada de grandes feixes intercalados por feixes menores (Fig. 7 B). Nos feixes, o xilema é superior ao floema, não sendo os dois contíguos. Estão quase totalmente envolvidos por uma grande capa de 
fibras fortemente espessadas em forma de meia-lua. As pontas das capas se tocam, formando uma figura parecida com o número oito, sendo que sua parte equatorial é constituída de fibras em espessamento. A capa do floema é maior que a do xilema e, este último, apresenta vasos com reforço escalariforme e helicoidal, parecendo o primeiro predominar sobre o segundo tipo. Encontra-se no mesofilo quatro camadas de ninhos de fibras esclerenquimáticas, com a seguinte constituição: duas camadas de ninhos constituídos de dez a trinta células, localizadas na periferia e situando-se entre as células da epiderme e hipoderme, com um intervalo de duas a quatro células de ninho para ninho, que possuem suas fibras fortemente espessadas, sendo que uma camada é adaxial e a outra abaxial. As outras duas camadas são formadas por ninhos constituídos de quatro a doze células, com fibras menores e menos espessadas, estando localizadas logo após as hipodermes, sendo uma superior e a outra inferior. Estas duas camadas de ninhos pequenos têm seus componentes intercalados com os feixes fibrovasculares (Fig. 7 A e B). Os feixes e os ninhos possuem em suas fibras periféricas grandes pontuações. Na região da margem da folha, notase sempre a presença de um feixe de fibras esclerenquimáticas de localização terminal antecedido de um canal. Nas demais regiões da folha, ocorre a mesma disposição dos tecidos descritos anteriormente.

4. Encyclia vespa (Vell.) Dressl.
Habitat e morfologia - Epífita e terrestre secundária, umbrófila a heliófila. Pseudobulbos presentes, bifoliada no ápice do pseudobulbo, folhas coriáceo-carnosas, suberetas, persistentes, oblongo-lanceoladas. alongadas, estreitas, ca. de $6-20 \mathrm{~cm}$ de comprimento, ca. de 2-4 de largura, raiz com velame.

\section{Descrição anatômica}

Epiderme - Ambas as epidermes, em vista frontal, são constituídas de células irregulares quanto ao formato e tamanho, com paredes retas, de espessura média, orientadas perpendicularmente ao comprimento foliar (Fig. 8 A e B). Em vista transversal, as epidermes são uniestratificadas, com células tabulares, aclorofiladas, sendo que as células da epiderme são maiores. Algumas células, nas duas epidermes, se esclerificam, assim como algumas apresentam vacúolos-ráfides com cristais de oxalato de cálcio. As epidermes estão recobertas por uma cutícula não muito espessa, ondulada e com ranhuras perpendiculares à epiderme, sendo que a cutícula da epiderme adaxial é mais grossa. As epidermes possuem pequenos espaços intercelulares pouco diferenciados, que são preenchidos pela cutícula. Nota-se a presença de pontuações conspícuas na parede periclinal interna das células da epiderme abaxial, assim como pontuações nas anticlinais de ambas as epidermes. As folhas são hipoestomáticas (média de 68,1 de estômatos por campo). Os estômatos são paracíticos, com distribuição 

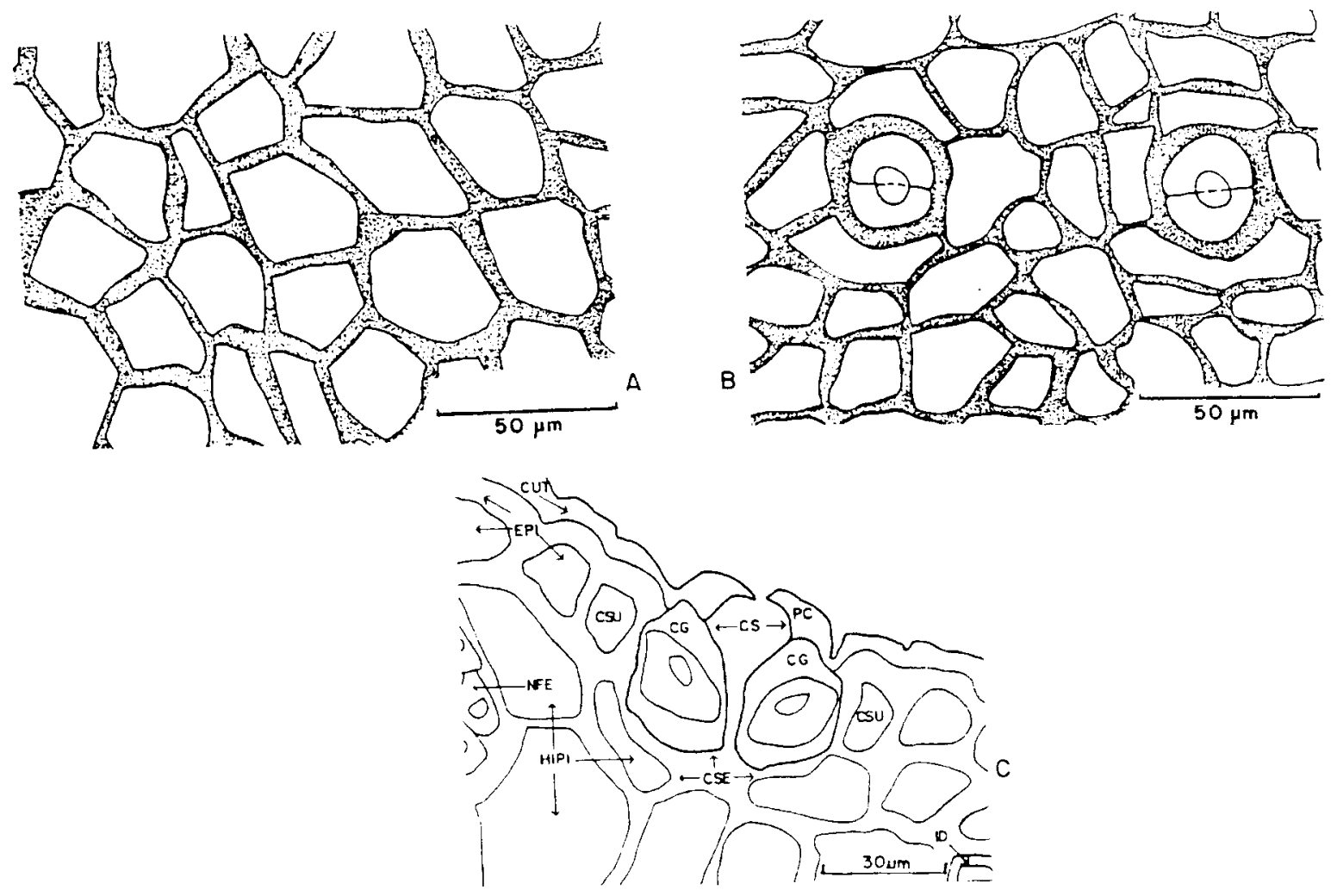

Figura 6. Folha de Encyclia tarumana Schltr. A: Epiderme adaxial em vista frontal. B: Epiderme abaxial. C: Corte transversal na face abaxial; CUT = Cutícula; $P C=$ Projeção cuticular; $C S=$ Câmara supraestomática; $C$ G = Células-guardas $\mathrm{CSU}=$ Células subsidiárias; $\mathrm{EPI}=$ Epiderme; $\mathrm{CSE}=\mathrm{Câmar}$ subestomática; $\mathrm{NFE}$ = Ninho de fibras esclerenquimáticas, $\mathrm{HIPI}=$ Hipoderme inferior; $\mathrm{ID}=$ Idioblasto 

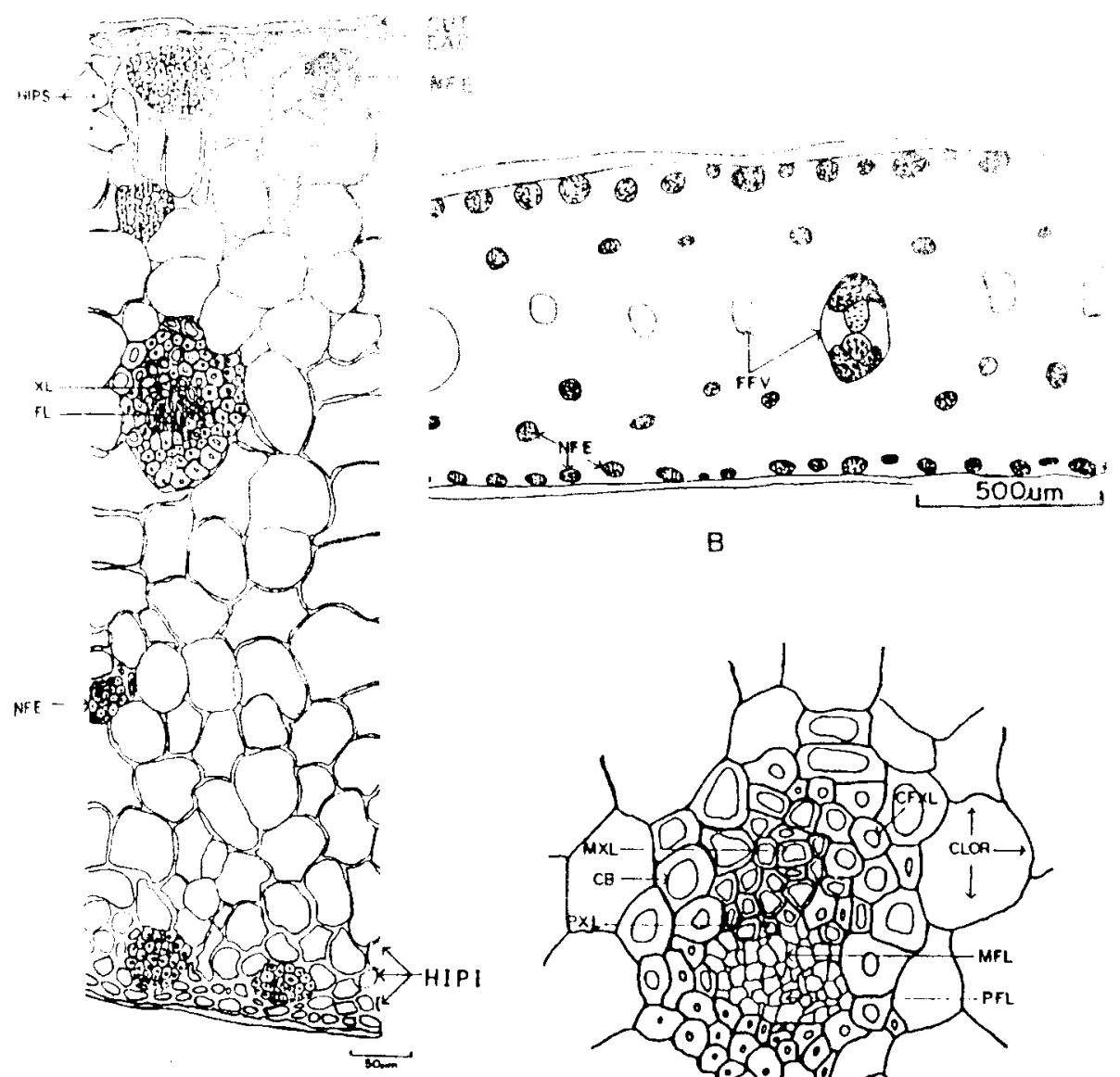

A

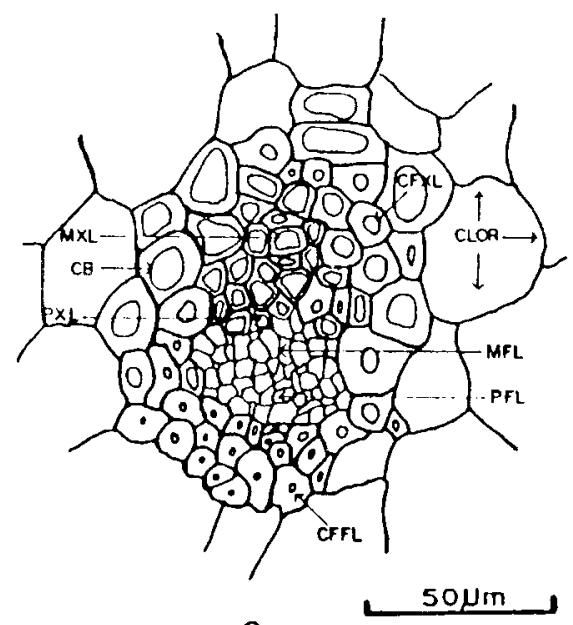

$\mathrm{C}$

Figura 7. Folha de Encyclia tarumana Schltr. A: Corte transversal na região do meio. CUT = Cuticula; EAD = Epiderme adaxial; NFE = Ninho de fibras esclerenquimáticas; HIPS = Hipoderme superior; $\mathrm{XL}=$ Xilema; FL = Floema; HIP = Hipoderme inferior; $\mathbf{B}$ : Corte transversal mostrando disposição dos tecidos de condução e sustentação. C: Corte transversal de um feixe fibrovascular; CLOR = Clorênquima; $\mathrm{CB}=$ Células da bainha; $\mathrm{CFLX}=$ Capa de fibras do xilema; $\mathrm{CFFL}$ = Capa de fibras do floema; $\mathrm{MXL}=$ Metaxilema; $\mathrm{PXL}=$ Protoxilema; $\mathrm{MFL}=$ Metafloema; PFL = Protofloema. 
paralela à nervura, esféricos e solitários, estando imersos na epiderme, possuindo câmaras subestomáticas e mostrando uma pequena mas acentuada projeção cuticular que, observada em corte transversal, em primeiro plano possui a forma de "garra", assim como um acentuado espessamento celulósico nas célulasguardas. A projeção cuticular forma pequenos poros de formato losangular a oblongo quando observada em vista frontal (Fig. 8 B e C). Ocorrem tricomas desde a base até o ápice da folha, de maneira inconstante, em ambas as epidermes, sendo mais abundantes na epiderme adaxial que na abaxial. Podem ser solitários ou não, pluricelulares, constituídos de duas a três células, sendo a base formada por duas células, estando imersa em depressões na epiderme, e o corpo por uma grande células que possui as paredes reforçadas e com o citoplasma mucilaginoso. Os tricomas são caliciformes e não apresentam características secretoras.

Hipoderme - A hipoderme adaxial é constituída de três camadas de células e a abaxial de duas camadas. Ambas as hipodermes apresentam células com espessamento secundário, células incolores e com pouco ou nenhum conteúdo e com raros cloroplastos (Fig. $8 \mathrm{C}, 9 \mathrm{~A}$ ).

Clorênquima - Situado logo abaixo das hipodermes, é homogêneo, com células poliédricas, de tamanho irregular, de paredes finas. Não são paralelas à epiderme, embora algumas células possuam um espassamento secundário paralelo à mesma. Possui suas células grandemente vacuolizadas e com citoplama bem periférico. Não apresenta uma clara distinção entre células paliçádicas e lacunosas, sendo que na região da nervura central as células tendem a alongar suas paredes anticlinais e, na região do mesofilo, por toda a folha, as células são mais isodiamétricas. O mesofilo é constituído de um compacto clorênquima, com espaços intercelulares, do tipo meato e de canais repletos de cristais. Células pétreas solitárias e fibras em espessamento, são encontradas no mesofilo inferior, na segunda camada de células a partir da hipoderme inferior, com um espaçamento de três células comuns do clorênquima entre si. Possui, ainda. células incolores, dispersas pelo clorênquima (Fig. 9 A). Os cloroplastos aparentam não possuir dimorfismos, estando agrupados ou não dentro do citoplasma, e estão distribuídos de maneira uniforme por todo o clorênquima.

Condução e sustentação - Os feixes fibrovasculares, formam duas camadas paralelas, com a seguinte configuração: partindo a nervura central, a camada mais inferior é constituída de grandes feixes e, acima desta. encontra-se a segunda camada, com feixes menores (Fig 9 B). Nos feixes. o xilema é superior ao floema, sendo um, contíguo ao outro. Estão arrodeados de parênquima esclereficado e de fibras, que nos polos se espessam fortemente formando capas, sendo que a do floema é maior que a do xilema. O xilema apresenta vasos com reforço 
escalariforme em predominância ao reforço helicoidal. Nota-se ainda uma grande disposição de cristais em redor de cada feixe fibrovascular (Fig. $9 \mathrm{~A}$ e B). Encontra-se no mesofilo superior, próximo à hipoderme, uma camada de pequenos ninhos de fibras esclerenquimáticas sendo que cada ninho possui em média dez fibras, que como as fibras periféricas dos feixes fibrovasculares, possuem grandes pontuações em sua periferia. Nas demais regiões da folha, ocorre a mesma disposição de tecidos descritos anteriormente. Griseb.

\section{Epidendrum compressum}

Habitat e morfologia - Epifítica a terrestre secundária ocasional na Campina sombreada, umbrófila e heliófila. Bifoliada, folhas articuladas com a bainha, persistentes, coriáceocarnosas, suberetas e arcuadas, lanceoladas, alongadas, estreitas, ca. de 6-14 cm de comprimento, ca. de 1-2 $\mathrm{cm}$ de largura, raiz com velame.

\section{Descrição anatômica}

Epiderme - Ambas as epidermes, em vista frontal, são constituídas de células irregulares quanto ao formato e tamanho, com paredes retas, espessas, orientadas perpendicularmente ao comprimento foliar (Fig. 10 $A$ e B). Em vista transversal as epidermes são uniestratificadas, com células filiformes, aclorofiladas, com as da epiderme adaxial de tamanho maior. As duas epidermes possuem um reforço de suberina em sua parede periclinal externa, sendo que as paredes anticlinais são mais espessas que as periclinais. Nota-se que na epiderme adaxial a parede periclinal interna é mais espessa que na epiderme abaxial e, comparando-se as paredes periclinais, observa-se que a externa é mais espessada que a interna, valendo a observação para ambas as epidermes. As folhas são hipoestomáticas (média de 56 estômatos por campo). Os estômatos são paracíticos, com distribuição paralela à nervura central, ovais, solitários. Localizam-se no mesmo nível das células da epiderme, possuindo câmaras subestomáticas e apresentando uma acentuada projeção cuticular que, observada em corte transversal, em primeiro plano, possui a forma de "garra". Nas célulasguardas não visualizou-se a presença de cloroplastos, possuindo as mesmas um acentuado espessamento celulósico. A projeção cuticular forma pequenos poros de formato arredondado à oblongo, quando observada em vista frontal (Fig. $10 \mathrm{~B}$ e C). Não foi notada a presença de tricomas.

Hipoderme - Logo abaixo das epidermes existe uma hipoderme. As hipodermes são compostas de duas camadas de células, sendo que a segunda camada se intercala com as células do clorênquima. As células são incolores, algumas com raros cloroplastos e possuindo paredes espessadas sendo que a hipoderme adaxial apresenta barras de espessamento secundário.

Clorênquima - Situado logo abaixo das hipodermes. É homogêneo, com células poliédricas de tamanho ir- 


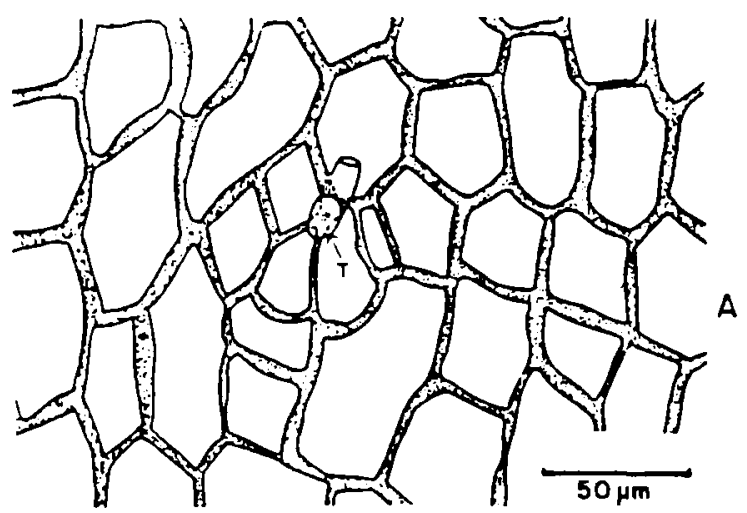

B
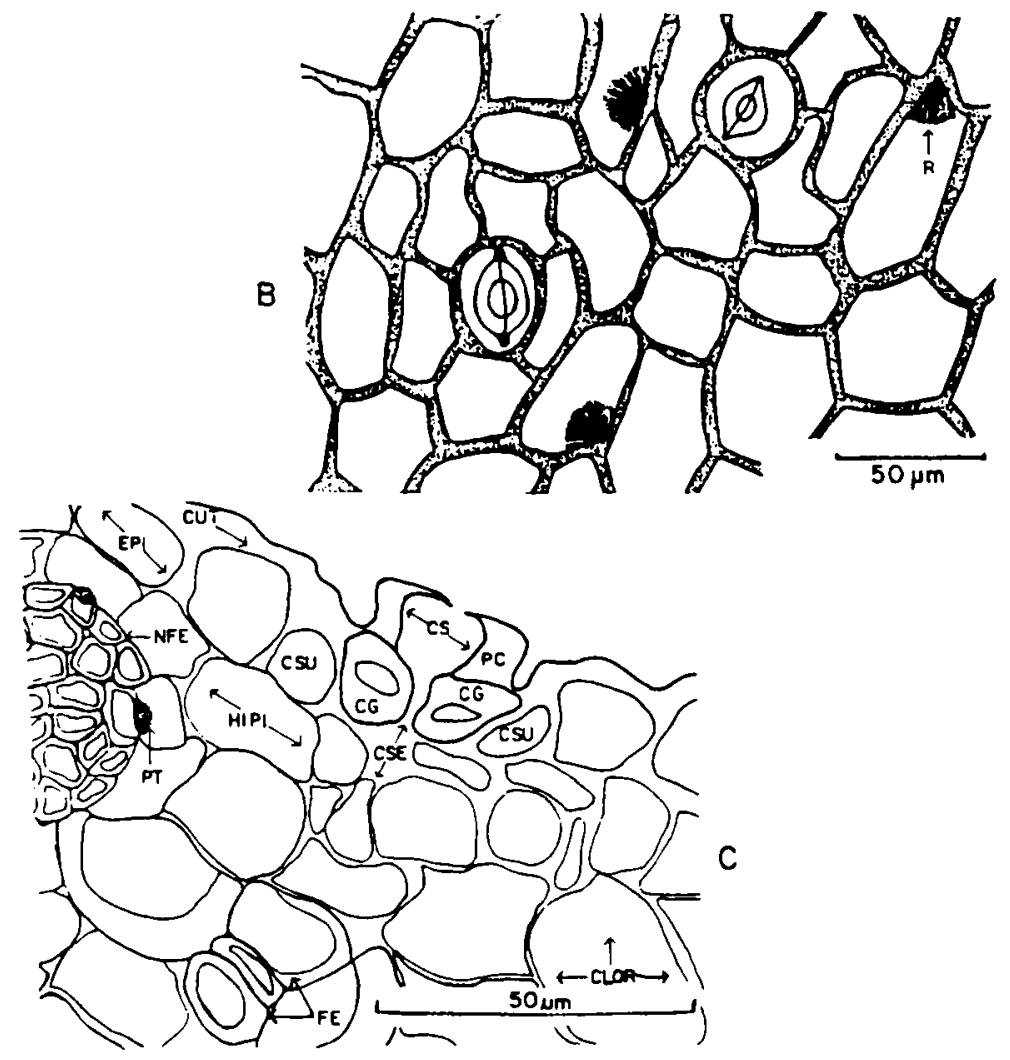

Figura 8. Folha de Encyclia vespa (Vell.) Dressl. A: Epiderme adaxial em vista frontal; $\mathrm{T}=$ tricoma. B: Epiderme abaxial; $\mathrm{R}$ $=$ Ráfide $\mathbf{C}$ : Corte transversal da face abaxial; CUT = Cutícula; $\mathrm{PC}=$ projeção cuticular; $\mathrm{CS}=$ Câmara suprestomática; CSE = Câmara subestomática; $\mathrm{CE}=$ Células-guardas; NFE = Ninho de fibras esclerenquimáticas; $\mathrm{PT}=$ Pontuaçōes; $\mathrm{PE}=$ Fibras de espessamento; CLOR = Clorênquima; HIPI $=$ Hipoderme inferior $;$ CSU $=$ Células subsidiárias . 




Figura 9. Folha de Encyclia vespa. A: Corte transversal na região do meio. CUT = Cutícula; $\mathrm{EAD}=$ Epiderme adaxial; HIPS = Hipoderme superior; $\mathrm{R}=$ Ráfides; $\mathrm{CLOR}=$ Clorênquima; $\mathrm{CFXL}=$ Capa de fibras do xilema; $\mathrm{PXL}=$ protoxilema; $\mathrm{MXL}=$ Metaxilema; $\mathrm{CB}=$ Células da bainha; $\mathrm{FE}=$ Fibras em espessamento; $\mathrm{FL}=$ Floema; $\mathrm{CFFL}=$ Capa de fibras do floema; $\mathrm{CML}$ = Canal mucilaginoso; $\mathrm{HIPl}=$ Hipoderme inferior; $\mathbf{B}$ : Corte transversal mostrando a disposição dos tecidos de condução e sutentação; NFE = Ninho de fibras esclerenquimáticas; FFV = Feixe fibra vascular. 
regular, com paredes finas, sendo que as células não são paralelas em relação às da epiderme. As células não mostram uma clara distinção entre células paliçádicas e lacunosas, excetuando-se as células da região da nervura central, onde as células do mesofilo superior tendem a alongar suas paredes anticlinais e nota-se que as células do mesofilo inferior são mais isodiamétricas. O mesofilo constitui-se, então, de um compacto clorênquima, com poucos espaços intercelulares do tipo meato (Fig. $11 \mathrm{~A}$ ). Os cloroplastos não aparentam possuir dimorfismos, estando agrupados ou não dentro do citoplasma e distribuídos de maneira uniforme por todo o clorênquima.

Condução e sustentação - Os feixes fibrovasculares possuem uma localização mediana, agrupando-se em três camadas paralelas assim dispostas: uma camada mediana formada de grandes feixes que se localiza ao mesmo nível da nervura central e as outras duas camadas, que são constituídas de pequenos feixes e localizam-se, uma superiormente e a outra inferiormente à camada mediana. Quando vistos transversalmente, estes feixes apresentam-se intercalados. Nos feixes fibrovasculares, o xilema é superior ao floema, sendo os dois separados por um fino cordão de fibras. Tanto o xilema quanto o floema são circundados por parênquima e fibras, possuindo em seus polos capas constituidas por fibras bastante espessadas, onde a capa de fibras do floema é bem desenvolvida em relação à do xilema. $\mathrm{O}$ xilema mostra vasos com reforço escala- riforme predominando sobre o helicoidal (Fig. 11 B). Existem diminutos ninhos de fibras esclerenquimáticas, constituindo-se de três a quatro fibras e dispersos no meio do mesofilo ou próximos à periferia, sendo que algumas delas não possuem um forte espessamento. As fibras constituintes dos ninhos, tais como as fibras periféricas dos feixes fibrovasculares, costumam possuir grandes pontuações em sua periferia. Nas demais regiões da folha ocorre a mesma disposição dos tecidos descritos anteriormente.

6. Epidendrum huebneri Schltr.

Habitat e morfologia

Pseudoterrestre na Campina aberta, sombreada, heliófila a umbrófila. Multifoliada, folhas com as bainhas coriáceo-carnosas, suberetas e arcuadas, persistentes, alternas, elípticas, alongadas, largas, ca. de $5-7 \mathrm{~cm}$ de comprimento ca. de $2 \mathrm{~cm}$ de largura, raiz com velame.

\section{Descrição anatômica}

Epiderme - Ambas as epidermes, em vista frontal, são constituídas de células irregulares quanto ao formato e tamanho, com paredes retas, espessadas, orientadas perpendicularmente ao comprimento foliar (Fig. 12 A e B). Em vista transversal, as epidermes são uniestratificadas, com células filiformes, aclorofiladas, com as da abaxial de tamanho maior. A duas epidermes possuem um reforço de suberina em sua parede periclinal externa, sendo as epidermes recobertas por uma espessa cutícula, que se apresenta ondulada na epiderme adaxial e ligeiramente lisa e 


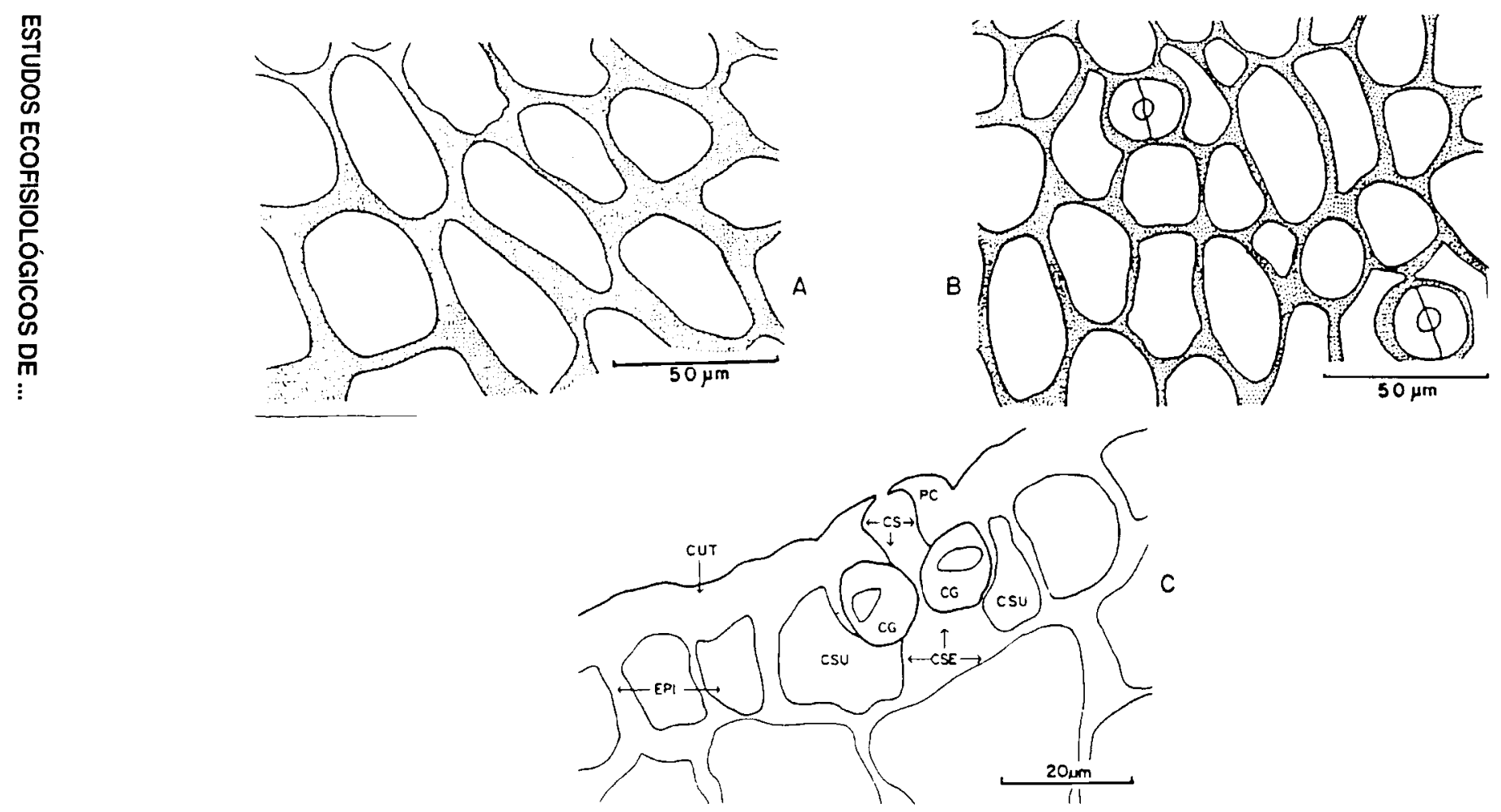

Figura 10. Folha de Epidendrum compressum Griseb. A: Epiderme adaxial em vista frontal. B: Epiderme adaxial. C: Corte transversal na face abaxial; CUT = Cutícula; $\mathrm{PC}=$ Projeção cuticular; $\mathrm{CG}=$ Células-guardas; $\mathrm{CS}=$ Câmara supraestomática; $\mathrm{CSE}=$ Câmara subestomática; $\mathrm{CSU}=$ Células subsidiárias; $\mathrm{EPI}=$ Epiderme . 

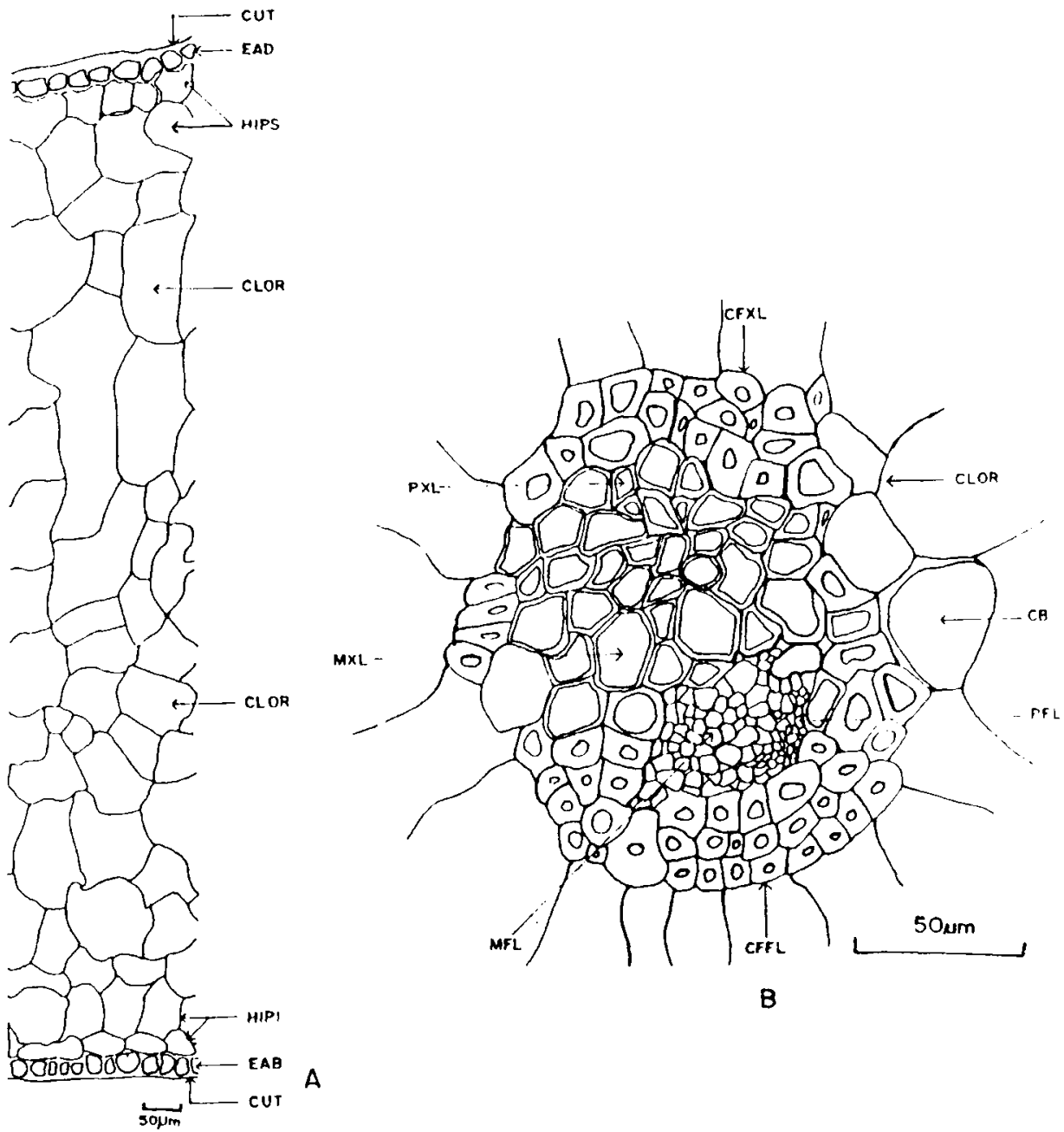

B

A

Figura 11. Folha de Epidendrum compressum Griseb. A: Corte transversal da regiāo do meio. CUT = Cutícula; EAD = Epiderme adaxial; HIPS = Hipoderme superior; CLOR = Clorênquima; HIPI $=$ Hipoderme inferior, $\mathrm{EAB}=$ Epiderme abaxial. $\mathbf{B}$ : Corte transversal de um feixe fibrovascular: CFXL = Capa de fibras de xilema; $C L O R=$ Clorênquima; $C B=$ Células de bainha; PFL $=$ Protofloema MFL = Metafloema, $\mathrm{CFFL}=$ Capa de fibras do floema; $\mathrm{MXL}=$ Metaxilema; PXL $=$ Protoxilema 
mais espessa na adaxial, apresentando nas duas, ranhuras perpendiculares à epiderme. As epidermes apresentam pequenos espaços intercelulares pouco diferenciados que são preenchidos pela cutícula. As folhas são hipoestomáticas (média de 42 estômatos por campo). Os estômatos são paracíticos, com distribuição paralela à nervura central, esféricos e solitários. Localizam-se ao mesmo nível das células de epiderme, possuindo câmaras subestomáticas e supraestomáticas, mostrando uma acentuada projeção cuticular que, observada em corte transversal, em primeiro plano, possui a forma de "garra". Não foi notada a presença de cloroplastos nas célulasguardas, que possuem um acentuado espessamento celulósico. A projeção cuticular forma pequenos poros de formato arredondado à oblongo, quando observada em vista frontal (Fig. $12 \mathrm{~B} \mathrm{e}$ C). Não foi notada a presença de tricomas.

Hipoderme - Existe uma epiderme esclerificada com células de citoplasma incolor, aclorofiladas, com pontuações nas suas paredes anticlinais e um espessamento acentuado de lignina. A hipoderme adaxial é composta de uma a duas camadas de células, sendo a adaxial composta de duas a três camadas de células (Figs. 12 C, $13 \mathrm{~A}$ ).

Clorênquima - Situado logo abaixo dos hipodermes. É relativamente homogêneo com células poliédricas, de tamanho irregular, com paredes finas, sendo que as células não são paralelas com as da epiderme. As células não mostram uma distinção entre células paliçádicas e lacunosas, excetuando-se as células na região de nervura central, onde as células do mesofilo superior tendem a alongar suas paredes anticlinais e nota-se que as células do mesofilo inferior são mais isodiamétricas. O mesofilo constitui-se de um compacto clorênquima, com poucos espaços intercelulares do tipo meato e com células com barras de espessamento de lignina e espessamento secundário em várias células do mesofilo. Os cloroplastos aparentam não possuir dimorfismos, estando agrupados ou não dentro do citoplasma e distribuídos de maneira uniforme por todo o colênquima. É bastante comum a presença de vacúolosráfides dispersos pelo clorênquima, sendo que na margem da folha a presença deles é bastante constante.

Condução e sustentação - Os feixes fibrovasculares formam uma única camada mediana de pequenos e grandes feixes, que intercalam-se a partir de nervura central (Fig. 13 B). O xilema é superior ao floema, sendo os dois separados por um fino cordão de fibras. Tanto o floema quanto o xilema são circundados por parênquima esclerificado e fibras, que nos polos dos feixes se espessam intensamente formando capas, sendo que a capa do floema é mais desenvolvida que a do xilema. O xilema mostra vasos com reforço escalariforme predominando sobre o helicoidal (Fig. 13 C). Existem ninhos de fibras esclerenquimáticas por toda a folha. Estes ninhos são periféricos, e estão inseridos nas hipodermes com suas células entrando em contato com as da epiderme e as do mesofilo. Os ninhos são constituídos, em média, 
de vinte células, estando separados uns dos outros por duas a três células hipodérmicas. As fibras esféricas dos feixes fibrovasculares e dos ninhos de fibras possuem grandes pontuações. Nas demais regiões da folha, ocorre a mesma disposição dos tecidos descritos anteriormente.

Considerações sobre a metodologia utilizada na anatomia e de alguns dos caracteres anatômicos das Orchidaceae do estrato terrestre de vegetação de Campina.

A anatomia de Monocotiledôneas é trabalhosa no que se refere à metodologia para efetuar cortes anatômicos, principalmente em se tratando de plantas com folhas carnosas. A diluição de cola vinílica em água, citada em nossa metodologia, é uma das maneiras que encontramos de superar este problema, pois os mesofilos das espécies com folhas carnosas possuem uma grande quantidade de água, e as das folhas plicadas, possuem uma fragilidade muito grande quando trabalhadas em parafina. Neste aspecto, a microtomia de congelação mostrou-se uma boa ferramenta. Para se evitar o colapso das células quando trabalhadas com microtomia de parafina, tornou-se necessário controlar cuidadosamente a temperatura, sendo que o emprego da técnica do banhomaria é bastante eficaz para as espécies estudadas. O Verniz-Cristal mostrou-se um ótimo substituto do Bálsamo d Canadá. nas montagens das lâminas histológicas, tanto na microtomia de parafina, quanto na de congelação, desde que inexistam traços residuais de benzol ou álcool.

BRAGA \& VILHENA (1981), classificaram o estômato de Epidendrum huebneri Schltr., como sendo do tipo tetracítico e, aqui, classificou-se como paracítico. Se considerarmos o formato das quatro células que envolvem o poro estomático, aparentemente pode-se classificar o estômato como tetracítico, mas quando usa-se astrablau-fucsina para a coloração epidérmica, nota-se que somente duas células são paralelas ao eixo longitudinal, e que coram-se de maneira diferente das células epidérmicas, indicando a existência de um possível comportamento fisiológico diferente, no tocante à relação forma-função.

As espécies estudadas apresentaram seus estômatos com uma ou mais células subsidiárias flanqueando os estômatos paralelamente ao eixo longitudinal das células-guardas, sendo classificados de paracíticos. Seria interessante desenvolver estudos para a elaboração de uma possível classificação estomática baseada na morfo-fisiologia das células subsidiárias que fazem parte do complexo estomático em Orchidaceae. A separação através de sais corantes, associada ao estudo morfológico detalhado, parece ser o método aconselhável para quem quiser empreender um estudo neste sentido.

A presença de vacúolos-ráfides constantes e com localização específica nas espécies estudadas dos gêneros Encyclia e Epidendrum sugerem que os mesmos possam ter algum valor numa diagnose taxonômica. 

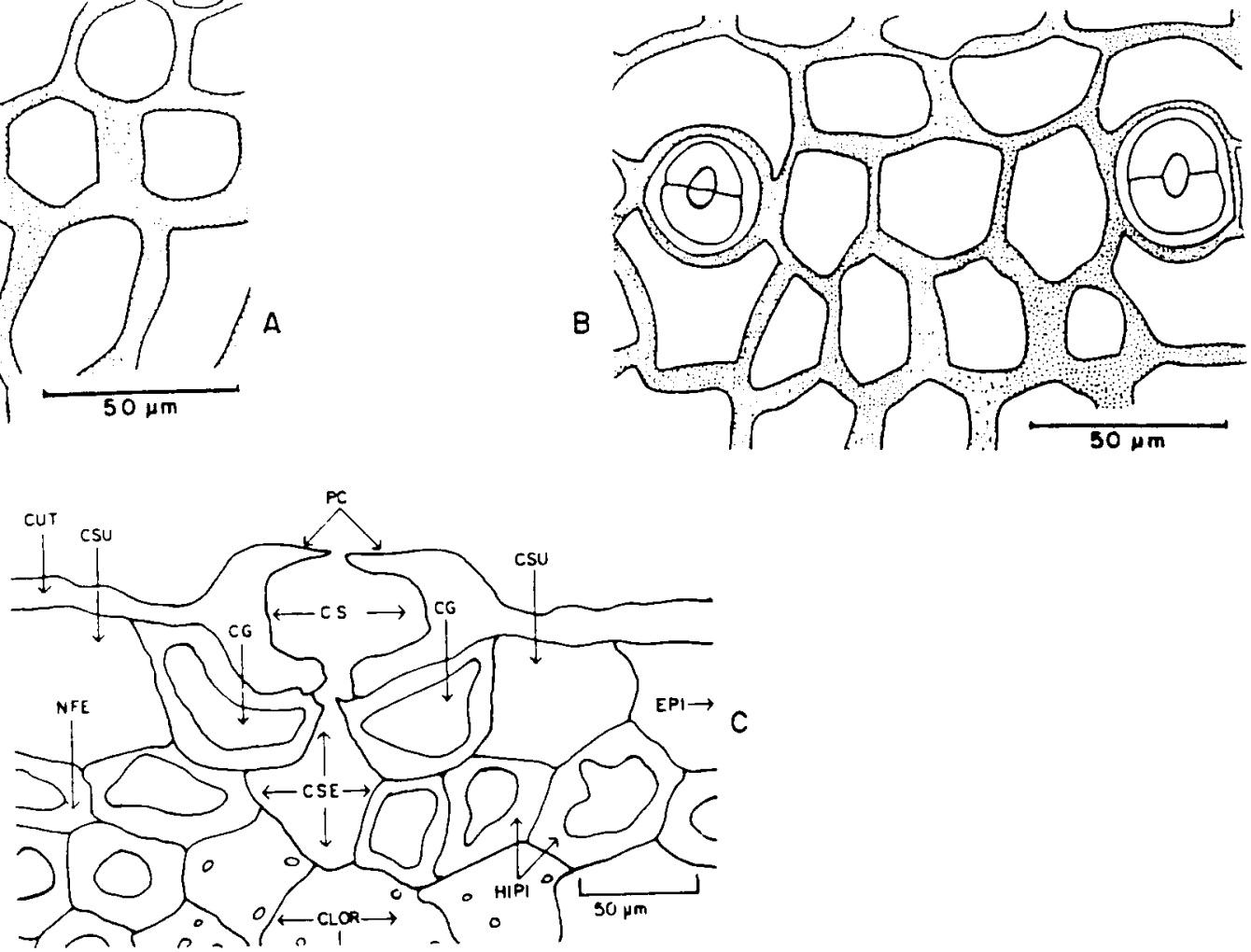

Figura 12. Folha de Epidendrum huebneri Schltr. A: Epiderme adaxial em vista frontal. B: Epiderme abaxial. C: Corte transversal da face abaxial; CUT = Cutícula; CSU = Célula subsidiária; $P C=$ Projeção cuticular; $C G=$ Célula-guarda; $C S$ = Câmara supraestomática; CSE = Câmara subestomática: EPI = Epiderme; HIPI = Hipoderme inferior; NFE = Ninho de fibras esclerenquimáticas; CLOR = Clorênquima. 


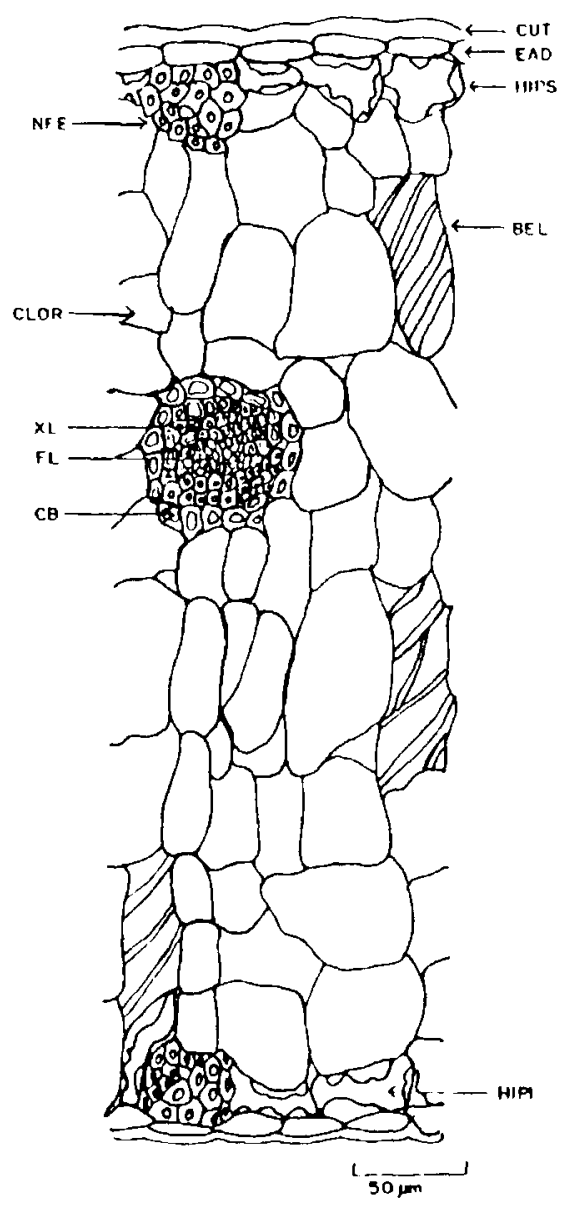

$A$
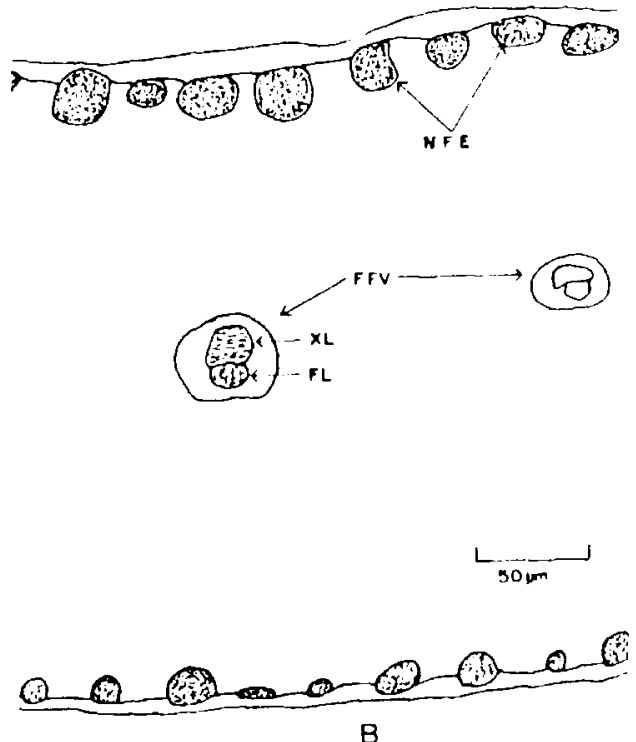

$\mathrm{B}$

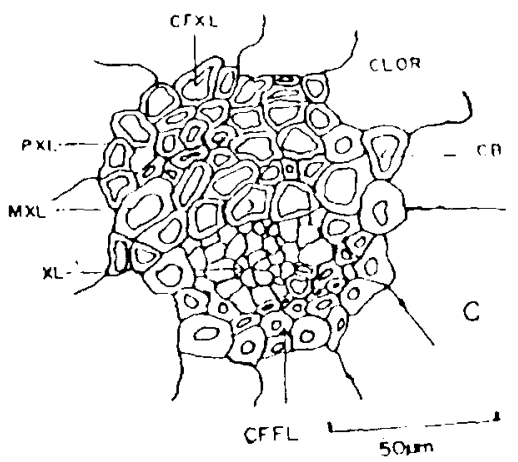

Figura 13. Folha de Epidendrum huebneri Schltr. em corte transversal. A: Regiāo do meio; CLT = Cuticula; $\mathrm{EAD}=$ Epiderme adaxial; $\mathrm{HIPS}=$ Hipoderme superior: BEL = Barra de espessamento de lignina: Hipoderme inferior: $\mathrm{CB}=$ Célula da bainha: $\mathrm{FL}=$ Floema: $\mathrm{XL}=\mathrm{Xilema:} \mathbf{B}$ : Corte Transversal mostrando a disposição dos tecidos de condução e sustentação: NFE = Ninhos de fibras esclerenquimáticas; $\mathrm{XL}=$ Xilema; $\mathrm{FL}=$ Floema. C: Feixe fibrovascular: $\mathrm{CFXL}=$ Capa de fibras do xilema; $C L O R=$ Clorênquima: $C B=$ Células da bainha: $C F F L=C$ apa de fibras do floema; $\mathrm{XL}=$ Xilema; $\mathrm{PXL}=$ Protoxilema; $\mathrm{MXL}=$ Metaxilema. 
Na tabela 2 apresenta-se um quadro sinóptico com as características anatômicas encontradas nas seis espécies estudadas, que enquadram suas folhas como pertencentes aos tipos coriácea dura, coriácea carnosa, conforme classificação modificada de WITHNER et al. (1974).

\section{DISCUSSÃO E CONCLUSÕES}

Mesofilo com células grandemente vacuolizadas, incolores, sem cloroplastos, relacionadas a estocagem de água, hipoderme presente e cloroplastos sem dimorfismos detectadas nas espécies estudadas, conferem as mesmas uma





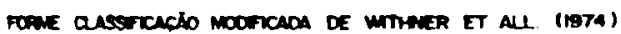

\begin{tabular}{|c|c|c|}
\hline & CARACTERISTICAS & 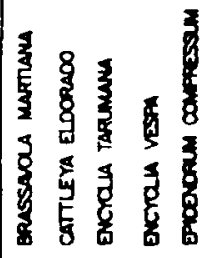 \\
\hline 1 & FOLKAS MAO PUCADAS & 70 \\
\hline 2 & RAOHAM OU ESTALAM OMANDO DOERMOAS & 00 \\
\hline 3 & SUPEAFICE ASPERA OU RUCOOSA NO TATO & 000 \\
\hline 4 & CILINOAICAS & $\bullet$ \\
\hline 3 & cuticar Aspessa & $\because 00$ \\
\hline 6 & 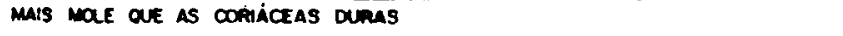 & $\bullet$ \\
\hline 7 & 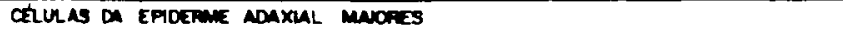 & 1 \\
\hline B & 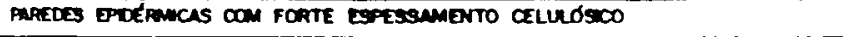 & $\boldsymbol{\nabla}$ \\
\hline 9 & 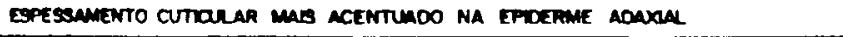 & -10 \\
\hline 10 & CLLULAS EPIOERMICAS ESCLERTICAONS & 00 \\
\hline 11 & SEM TreOMMS & 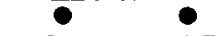 \\
\hline 12 & CON Tricomins & 0 \\
\hline 13 & mpoessomanca & 10 \\
\hline 14 & cimen suoestonatica & 00 \\
\hline 13 & hootinante & 00 \\
\hline 16 & 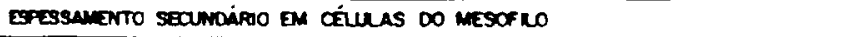 & -10 \\
\hline 17 &  & 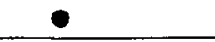 \\
\hline $\mathbf{1}$ & CHULAS ESOERIFICAOAS NO MESOTLO & - \\
\hline 19 & CEULA dO MESOFXO SUFERKO TENDENDO a ALONGADAS & - \\
\hline 20 & 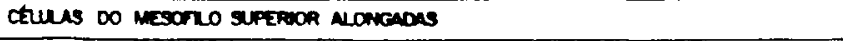 & - \\
\hline 21 & 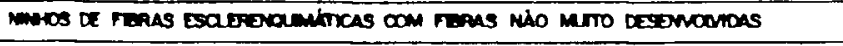 & $\nabla$ \\
\hline 22 &  & 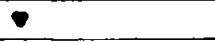 \\
\hline 23 & 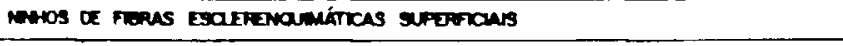 & -1 \\
\hline 24 & 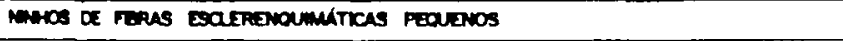 & - \\
\hline 20 & 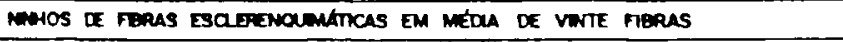 & 10 \\
\hline 20 & 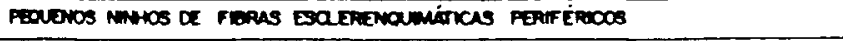 & $\bullet$ \\
\hline 27 &  & - \\
\hline 20 &  & $\boldsymbol{\nabla}$ \\
\hline
\end{tabular}


suculência morfo-anatômica necessária para a ocorrência do metabolismo CAM. A presente avaliação desta suculência nestas espécies discriminadas como CAM, no primeiro trabalho desta série (BONATES \& BRAGA, 1992), contribui para reforçar com uma análise qualitativa, a validade dos métodos quantitativos adotados por estes autores no citado trabalho, assim como, somadas com as características anatômicas da tabela 2 , permitem o enquadramento das folhas destas espécies na classificação baseada em WITHNER et al. (1974) que divide anatomicamente as folhas de Orchidaceae em dois grupos, a saber: folhas plicadas ou com "costelas", e folhas coriáceas, com os subtipos mole, duro, carnoso. Esta classificação, ao contrário das primeiras revisões anatômicas sobre Orchidaceae (como as de SOLEREDER \& MEYER, 1930 apud WITHNER et al. 1974), preocupa-se em analisar os caracteres anatômicos sob parâmetros evolutivos e ecológicos, que buscam informar sobre o crescimento, desenvolvimento e derivações das Orchidaceae. A divisão entre folhas plicadas e coriáceas é absoluta. As folhas plicadas são caracteristicamente delgadas, membranosas e decíduas, sendo sua função precípua, a realização da fotossíntese, pois a retenção da água seria realizada por pseudobulbos, raízes com velame ou camosas, prestando-se à primeira vitsa, para ocupar nichos úmidos e pouco ensolarados. Já as folhas classificadas como Coriáceas (dura, mole e carnosa) apresentam uma robustez e dureza maior em relação ao tipo Plicada, e são folhas persistentes. Sua caracteri- zação anatômica é bem mais heterogênea e frequiente nas Orchidaceae.

A função da folha do tipo Coriácea não seria só a de efetuar fotossíntese, mas também a de funcionar como um órgão armazenador de água, armazenagem esta que se torna mais eficiente quando acompanhada de órgãos como pseudobulbos, raiz com velame e outros, prestando-se assim, a folha Coriácea, para ocupar nichos mais ensolarados e de condições mais xéricas.

As barras de espessamento encontradas no mesofilo de $C$. eldorado, E. compressum e E. huebneri são aqui interpretadas desempenhando a função de coadjuvante na sustentação foliar e de contenção do fluxo hídrico entre as células, assim como a existência de cristais de oxalato de cálcio em forma de ráfides em $B$. martiana, $C$. eldorado, E. vespa e E. huebneri pode estar relacionada com o balanço iônico e osmoregulação. A ocorrência de projeção cuticular é comum na anatomia foliar de Orchidaceae sendo que as mesmas tendem a serem mais acentuadas nas espécies que habitam ambientes mais xéricos. A pequena incidência e a distribuição esparsa de pelos em E. tarumana e E. vespa sugere que estes não estão relacionados diretamente com o controle da transpiração foliar.

A correlação entre folhas hipoestomáticas e anfistomáticas. tamanho, formato e função dos poros formados pelas projeções cuticulares e a estrutura dos estômatos, poderá ser vista no sexto trabalho desta série (em preparação). 
Como mencionou-se anteriormente, caracteres aparentemente xeromórficos nem sempre indicam xerofilia. Eles também são comuns em condições de esclerofilia, relacionada com a pobreza de nutrientes no solo ou com grande quantidade de alumínio no solo. A Tabela 3 apresenta caracteres anatômicos relacionados com xeromorfismo habitacional e/ou escleromorfismo nutricional das espécies estudadas. Seria necessário um estudo mais acurado e específico para estabelecer o nível onde cada caracter influencia no fator escleromorfismo ou xeromorfismo.

A presença de células relacionadas com a armazenagem de água, ninhos de fibras esclerenquimáticas, idioblastos, capas de fibras envolvendo os tecidos de condução, parênquima esclerificado, pontuações periféricas nas fibras esclerenquimáticas, assim como linhas de pontuações nas células epidérmicas, levam a acreditar que possivelmente todas as características se relacionem com uma síndrome anatômica adaptativa, para um efetivo controle de fluxo hídrico dentro do limbo foliar, protegendo assim a sua configuração contra um colapso da estrutura celular (principalmente das paredes) provocado por um "stress" hídrico, dando condições para as espécies estudadas colonizar ambientes mais xéricos como os da Campina Aberta. Estes caracteres e outros listados nas Tabelas 2 e 4 , conferem às folhas das espécies estudadas uma classificação de folhas Coriáceas e com suculência anatomicamente detectável, conferindo à folha como um todo, não só a função fotossintéti-

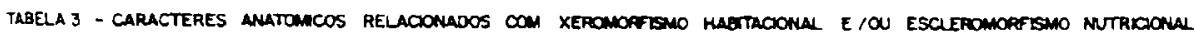



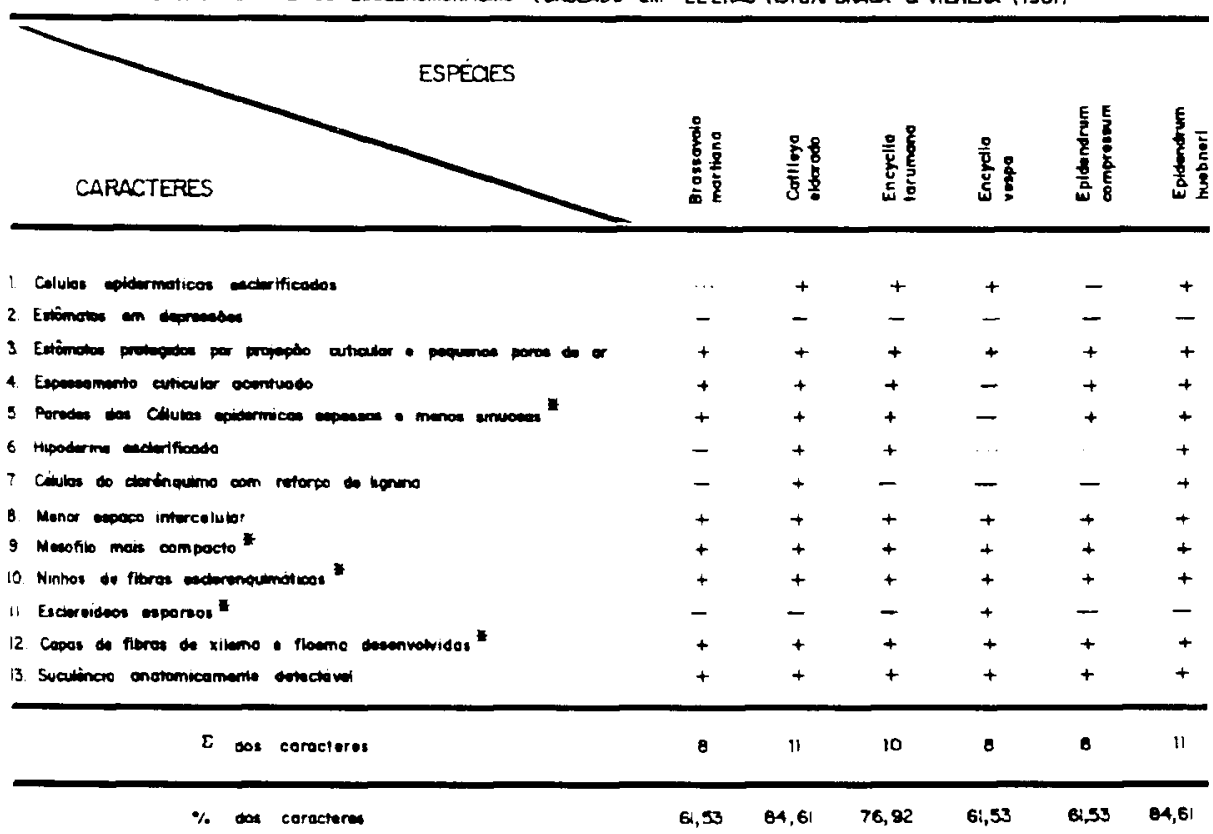




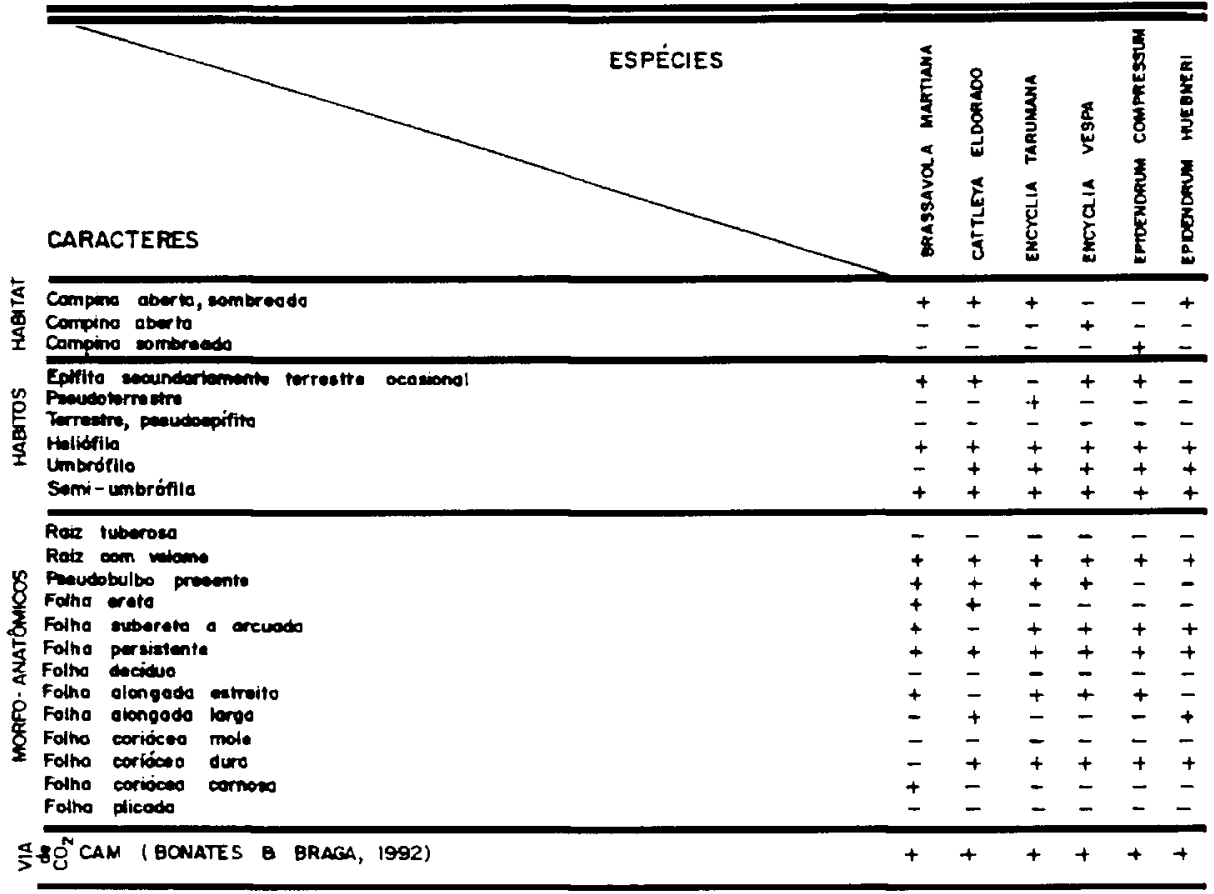

ca, mas também a de armazenagem de água e possuidoras de carcaterísticas morfológicas propícias para a ocorrência do metabolismo CAM

\section{Literatura Citada}

AVADAHANI, P. N; GOH, G. J.; RAO, A. N.; ARDITTI, J. 1980. Carbon fixation in Orchids. In: Orchid Biology - Reviews and perspectives, II. Edites by Joseph Arditti Comstock Publishing Associates. 175-183.

BRAGA, M. M. N. 1977. Anatomia foliar de Bromeliaceae da Campina. Acta Amazonica, 9(3), Supl. 74 p.

BRAGA, M. M. N.; BRAGA, P. I. S. 1975. Estudos sobre a vegetação das Campinas Amazônicas, IV - Estudos ecológicos na Campinas da Reserva Biológica do
INPA/SUFRAMA, $\mathrm{Km}$ 45. Acta Amazonica, 5(3):247-260.

BRAGA, P. I. S. 1977. Aspectos biológicos das Orchidaceae de uma Campina da Amazônia Central. Acta Amazonica. 7(2). Supl. 89 p.

1982b. Aspectos biológicos das Orchidaceae de uma Campina da Amazônia Central. II - Fitogeografia das Campinas da Amazónia Brasileira. Manaus. Tese de Doutorado, INPA/FUA. 345p.

1987a. Orquídeas - Entrada e Dispensão na Amazônia. Ciênc. Hoje, 5(28):44-51

BRAGA, P. I. S.; VILHENA, R. C. Q. 1981 Estudos sobre a vegetaçāo de Campinas Amazônicas. VII - Anatomia ccológica de Epidendram hucbneri Schltr. (Orchidaceac) e Phthinusa micruntha Eichl. (Loranthaceik). In: Anais do $1^{\circ}$ Encontro de Orquidóloges do Brasil. Rio de Janeiro Expressão e Cultura. 86-106. 
BONATES, L. M. C.; BRAGA, P. I. S. 1992. Estudos Ecofisiológicos de Orchidaceae da Amazônia I. Identificação da via C3 e CAM em quatorze espécies que vegetam no estrato terrestre de uma Campina da Amazônia Central. Bol. Mus. Para. Emílio Goeldi. Ser. Botânica, 8(2): 163-189.

COOMBS, J.; HALL, D. O. 1987. Técnicas de bioprodutividade e fotossíntese. Fortaleza. Ed. UFC. 292 p.

COUTINHO, L. M. 1969. Novas observações sobre a ocorrência de "Efeito de De Saussure" e suas relações com a suculência, a temperatura e os movimentos estomáticos. Bol. Fac. Fil. Ciênc. Letr. USP. Botânica, 331(24):77-102.

FERRI, M. G. 1960. Contributions to the Knowledge of the ecology of the "Rio Negro" Caatinga (Amazonas). Bull. Res. Counc. of Israel, 8D (3-4):195-208.

GOODLAND, R. 1971. Oligotrofismo e alumínio no Cerrado. In: $I I I$ Simpósio sobre o Cerrado. Coord. M. G. Ferri. Ed. Blucher. \& Ed. USP. 44-60.

JOHANSEN, D. A. 1940. Plant Microtechique. Tata McGraw Hill Publishing Company Ltd. Bombay - New Delli, 2 ed. 532 p.

LLERAS, E. 1978. Aspectos Básicos da morfologia e anatomia das folhas e sua relação com parâmetros fisiológicos. Anais do II Congresso Latino-Americano de Botânica. Brasília, Brasil.

MAXIMOV, N. A. 1931. The physiological significance of the xeromorphic structure of plants. Jour. Ecol., 19:273-282.

MEDINA, E. 1974. Dark $\mathrm{CO}_{2}$ fixation habitat preference and evolution within the Bromeliaceae. Evolut., 28:677-686.

1977. Introducion a la ecofisiologia vegetal. Prog. Reg. O. E. A. 102 p.

MEDINA, E. 1987. Aspectos ecofisiológicos de plantas CAM en los trópicos. In: Ecologia y ecofisiologia de plantas en los bosques meso americanos. Ed. Manuel Chavanía \& Julian M. N. 55-70.

MEDINA, E.; GARCIA, V.; CUENCAS, E. 1990. Sclerophylly and oligotrophic environments: Relationships between leaf structure mineral nutrient content and drought resistance in tropical rain forest of upper Rio Negro Region. Biotrop., 22(1):51-64.

MEDRI, M. E. 1977. Alguns aspectos da anatomia ecológica de folluss de Hevea brasiliensis Muell. Arg., Tese de Mestrado. INPA/FUA. $108 \mathrm{p}$

1980. Anatomia comparada e correlações Anátomo-fisio-ecológicas de clones de Hevea spp. Tese de Doutorado. INPA/ FUA. 428 p.

MORRETES, B. L.: FERRI, M. G. 1972. Contribuição ao conhecimento da anatomia de folhas de plantas de uma "Caatinga do Rio Negro". Rev. Biolog., 8(1-4):97-122.

PABST, G. J. F.; DUNGS, F. 1975. Orchidaceae brasiliensis, 1. Hildesheim, Brucke-Verlag. Kurt Schmerson. 408 p.

1977. Orchidaceae brasiliensis, 2. Hildesheim, Brucke-Verlag. Kurt Schmerson. 418 p.

PRIDGEON, A. M. 1982. Diagnostic Anatomical charactere in the Pleurothallidianae (Orchidaceae). Amer. J. Bot., 69(6): 921-938.

RASMUSSEN, H. 1987. Orchid StomataStructure, Differentiation, Function, and Phylogeny. In: Orchid Biology-Reviews and Perspectives, edited by $\mathrm{J}$. Arditti, London, Cornell University Press, Vol. IV, 106-138.

RIBEIRO, M. N. G.; SANTOS, A. 1975. Observaçōes macroclimáticas no ecossistema Campina Amazônia. Acta Amazonica, 5(2):183-189.

SOLEREDER, H.; MEYER. F. 1930. Systematische Anatomie der Monokotyledonem. 6:92-242 (apud Withner, G. L.; Nelson, P. K. \& Wejksnoram P. J. 1974. The anatomy of orchids. In: The orchids, scientific studies, edited by C. K. Withner. New York, John. Wiley. 208-209.

VILHENA, R. 1978. Anatomia foliar de três espécies da família Humiriaceae. Acta Amazonica, 8(1):25-43. 
WITHNER, C. L.; NELSON, P. K.; WEJKSNORA, P. J. 1974. The anatomy of orchids. In: The orchids, scientifics studies, edited by C. L. Withner, New York, John Wiley. 347-367.

WIESBERG, L. H. G. 1981. O teor de Carbono 13 como indicador do tipo de metabo- lismo na fixação de $\mathrm{CO}_{2}$ por orquídeas. In: Anais do $I^{\circ}$ Encontro de Orquidófilos e Orquidólogos do Brasil. Rio de Janeiro, Expressão e Cultura. 127-138.

ZIENGENSPECK, H. 1938. Filogenia dos estômatos. Bot. Arch., 39:286-306. 